\title{
RELACIONES EXTERNAS COMERCIALES DE LA UNIÓN EUROPEA CON ESTADOS UNIDOS
}

Fecha de Entrega: Noviembre de 2008 Fecha de Aprobación: Febrero 29 de 2009.

ELISA URBINA SÁNCHEZ. Economista Universidad del Rosario, Especialización en Economía Internacional de la Universidad del Rosario, Maestría en Derecho Público de la Universidad Santo Tomás, Doctorando Unión Europea en la UNED, Docente Investigadora de la Universidad Santo Tomás.

E mail: elisaurbina@usantotomas.edu.co

\section{RESUMEN}

Las decisiones multilaterales están determinadas hoy por el poder económico de la Unión Europea y Estados Unidos. Estas se han desarrollado en los últimos años a través de los Acuerdos firmados desde 1990 hasta el 2009. Los elementos principales de negociación son los desafíos globales y la expansión del comercio mundial. En enero de 2007 intensificó sus relaciones económicas hacia una asociación económica trasatlántica. El interés de la competitividad global les ha permitido seguir removiendo las barreras comerciales, por ejemplo en la legislación de patentes, estándares industriales o en el acceso a los mercados de bolsa. Un mercado común trasatlántico serviría eficazmente al interés de Europa. 
REVISTA VIRTUAL VIA INVENIENDI ET IUDICANDI

"CAMINO DEL HALLAZGO Y DEL JUICIO"

http://viei.usta.edu.co/ E-MAIL: revistainveniendi@usantotomas.edu.co

\section{PALABRAS CLAVES:}

Acuerdo comercial entre Estados Unidos y Unión Europea, Balanza Comercial y la Organización Mundial del Comercio.

\section{ABSTRACT}

The multilateral decisions are determined today by the economic power of the United States and the European Union. These have developed in the last years though the signed agreements since 1990 until 2009. The principal elements of negotiation are the global challenges and the expansion of the global commerce. In January 2007 their economic relationships intensified towards a transatlantic economic association. The interest in the global competition allows them to keep removing the commercial barriers, for example the patent legislation, industrial standards or the access to the stock exchange. A common transatlantic market could serve efficiently to Europe.

\section{KEY WORDS}

Commercial agreement between the United States and Europe, Balance of Trade, Global Commerce Organization. 
REVISTA VIRTUAL VIA INVENIENDI ET IUDICANDI

"CAMINO DEL HALLAZGO Y DEL JUICIO"

http://viei.usta.edu.co/ E-MAIL: revistainveniendi@usantotomas.edu.co

\section{I -INTRODUCCIÓN}

La integración económica avanza en todo el mundo a un ritmo sin precedentes. El comercio es solamente un aspecto de los Tratados y los nexos con los elementos económicos, políticos y tecnológicos más generales son múltiples y complejos.

La inserción de los fenómenos de la Integración Regional y la Globalización en la economía de los países de Europa nos permite reflexionar como el crecimiento económico fue hacia adentro de la región hasta 1985, al primar las exportaciones entre los países de Europa y a partir del Acta Única (1986), el crecimiento económico ha dependido de la conjunción entre la Integración Regional y la globalización.

Los hechos económicos nos muestran simultáneamente la convivencia de dos fenómenos contrarios en cada país, por una parte, la Globalización o transnacionalización de la producción y de otra parte, la integración regional.

El comercio es importante para todo el mundo. La política comercial de la Unión Europea busca la armonización del comercio a nivel mundial. El Tratado Transatlántico con Estados Unidos nos muestra como negociaciones bilaterales y las multilaterales de la Organización Mundial del Comercio buscan la Globalización del comercio exterior.

En esta investigación se trata de resolver la siguiente pregunta: ¿Cómo las políticas comerciales bilaterales, Unión Europea y Estados Unidos, prevalecen en las negociaciones multilaterales en beneficio del crecimiento económico de cada uno de ellos? En primer lugar, analizaré las Políticas comerciales en los Tratados de la Unión Europea; en segundo lugar, las relaciones 
REVISTA VIRTUAL VIA INVENIENDI ET IUDICANDI

"CAMINO DEL HALLAZGO Y DEL JUICIO"

http://viei.usta.edu.co/ E-MAIL: revistainveniendi@usantotomas.edu.co

transatlánticas de Estados Unidos y la Unión Europea y en tercer lugar, las conclusiones.

II - políticas comerciales en los tratados de la unión EUROPEA:

El 25 de marzo de 2007 se conmemoraron 50 años de la firma del Tratado de Roma creador de la Comunidad Económica Europea, fuente del proceso integrador que ha desarrollado Europa. El 25 de marzo de 1957, Italia, Alemania, Francia, Bélgica, Holanda y Luxemburgo, firmaron el Tratado de las Comunidades Europeas: la Comunidad Económica Europea y la Comunidad Europea de la Energía Atómica ${ }^{1}$. La integración Regional económica hace referencia a la agrupación de varios países alrededor de una forma concreta de organización económica y comercial a través de la cooperación conjunta (Calvo Antonia, 2001). La evolución que han experimentado los procesos de integración regional en los últimos años, ha hecho que los Acuerdos se hayan concentrado alrededor de las siguientes formas: Área de Libre Comercio, Unión Aduanera, Mercado Común, Unión Económica y Unión monetaria y Política.

La integración en Europa, se inició con la propuesta lanzada, el 9 de mayo de 1950, por Robert Schuman, Ministro francés de Asuntos Exteriores. El Gobierno francés propuso que se sometiera el conjunto de la producción franco-alemana de carbón y de acero a una Alta Autoridad común, en una organización abierta a los demás países de Europa. La puesta en común de las producciones de

\footnotetext{
1 Años después, en 1972, se produjo la primera ampliación: Dinamarca, Irlanda y el Reino Unido entraron a formar parte de estas Comunidades. Sucesivas ampliaciones a Grecia (1981), España y Portugal (1986), Austria, Finlandia y Suecia (1995). La más grande ampliación realizada fue en 2004 con la incorporación de diez nuevos miembros (Chipre, Eslovaquia, Eslovenia, Estonia, Hungría, Letonia, Lituania, Malta, Polonia, República Checa) y la última extensión de la zona geográfica de integración es en el presente año, 2007, con la incorporación de Bulgaria y Rumania. La Unión Económica queda conformada por veintisiete (27) estados miembros y un país como candidato, Turquía.
} 


\section{REVISTA VIRTUAL VIA INVENIENDI ET IUDICANDI}

"CAMINO DEL HALLAZGO Y DEL JUICIO"

http://viei.usta.edu.co/ E-MAIL: revistainveniendi@usantotomas.edu.co

carbón y de acero consideró que garantizaría inmediatamente la creación de bases comunes de desarrollo económico, primera etapa de la federación europea, que cambió el destino de Europa. De este modo se llevó a cabo la fusión de intereses indispensables para la creación de una comunidad económica ${ }^{2}$ y se dio origen a una comunidad más amplia y más profunda entre países que durante tanto tiempo se habían enfrentado en divisiones sangrientas. El resultado de estas negociaciones fue la creación de la Comunidad Europea del Carbón y del Acero (CECA) ${ }^{3}$. El tratado fue firmado en Paris el 18 de abril de 1951 por Francia, la República Federal Alemana, Italia y los tres países del Benelux- Bélgica, países bajos y Luxemburgo-. Este tratado entró en vigencia en 1953 y terminó el 23 de julio de 2002.

En 1957, se inició el proceso de integración regional con el TRATADO DE ROMA $^{4}$ que "mediante el establecimiento entre sí de una unión aduanera, los Estados miembros se proponen contribuir, conforme al interés común, al desarrollo armonioso del comercio mundial, a la supresión progresiva de las restricciones a los intercambios internacionales y a la reducción de las barreras arancelarias" (Tratado de Roma, Política comercial común, Artículo 131).

La política comercial común tuvo en cuenta la incidencia favorable de la supresión de los derechos de aduana entre los Estados miembros y acordó un

\footnotetext{
${ }^{2}$ El Área de Libre Comercio es la forma más simple de integración y supone la completa eliminación de las barreras arancelarias y no arancelarias al comercio de bienes y servicios entre los países participantes

3 Nota: Otros ejemplos de integración regional en Europa fue el área de libre comercio ( EFTA O AELC) creada en 1959 por el Reino Unido, Suecia, Noruega, Dinamarca, Austria, Portugal, Irlanda y Suecia En 1986 ingreso Finlandia. En segundo lugar, Unión Aduanera entre Liechtenstein y Suiza.

${ }^{4}$ Artículo 110. Mediante el establecimiento entre sí de una unión aduanera, los Estados miembros se proponen contribuir, conforme al interés común, al desarrollo armonioso del comercio mundial, a la supresión progresiva de las restricciones a los intercambios internacionales y a la reducción de las barreras arancelarias. La política comercial común tendrá en cuenta la incidencia favorable que la supresión de los derechos de aduana entre los Estados miembros pueda tener en el aumento de la capacidad competitiva de las empresas de dichos Estados.
} 


\section{REVISTA VIRTUAL VIA INVENIENDI ET IUDICANDI}

"CAMINO DEL HALLAZGO Y DEL JUICIO"

http://viei.usta.edu.co/ E-MAIL: revistainveniendi@usantotomas.edu.co

proceso transitorio de 12 años para eliminar los aranceles que aumento la capacidad competitiva de las empresas de la Comunidad Europea. Los firmantes fueron los primeros ministros de Francia, Italia, Alemania, Bélgica, Holanda y Luxemburgo. Ante el éxito económico que trajo la mayor fluidez de los intercambios comerciales, en agosto de 1961, Inglaterra' Dinamarca, Noruega e Irlanda solicitaron adhesión al Comunidad Económica Europea con plenos derechos ${ }^{5}$.

El artículo 133 del Tratado de Roma decía que "la Política Comercial Común se basará en principios uniformes, particularmente por lo que se refiere a las modificaciones arancelarias, la celebración de acuerdos arancelarios y comerciales, la consecución de la uniformidad de las medidas de liberalización, la política de exportación, así como las medidas de protección comercial, y, entre ellas, las que deban adoptarse en caso de dumping y subvenciones". En la práctica, una serie de procedimientos de coordinación ad hoc permitió asociar a los estados miembros a cada una de las fases de la negociación. "En el caso de que deban negociarse acuerdos con uno o varios Estados u organizaciones internacionales, la Comisión presentará recomendaciones al Consejo, que la autorizará para iniciar las negociaciones necesarias. Corresponderá al Consejo y a la Comisión velar por que los acuerdos negociados sean compatibles con las políticas y normas internas de la Comunidad" (Tratado de Roma, 1957, artículo 133, ordinal 3).La política comercial de la Unión Europea, responde a unos intereses básicos: 1. Es un medio para difundir valores europeos: democracia, Estado de derecho, medio ambiente, respeto de los derechos sociales, etc. 2.

\footnotetext{
${ }^{5}$ En 1972 firmaron el tratado Gran Bretaña, Irlanda y Dinamarca; Noruega rechazó la entrada por referéndum de sus electores. En 1981 ingresó
} Grecia y en 1986, España y Portugal, quedando conformada la Comunidad Europea por 12 países. 


\section{REVISTA VIRTUAL VIA INVENIENDI ET IUDICANDI}

"CAMINO DEL HALLAZGO Y DEL JUICIO"

http://viei.usta.edu.co/ E-MAIL: revistainveniendi@usantotomas.edu.co

Busca la apertura de los mercados al comercio mundial: eliminación de barreras al comercio. 3. Pretende la inserción de todos los países en el sistema de comercio internacional (García Monserrat, 2007).

Otros elementos esenciales de lo acordado en el Tratado de Roma fue la adopción de una Política Agrícola Común (PAC). Esencialmente, estableció la libertad de circulación de los productos agrícolas dentro de la Comunidad Económica Europea y la adopción de políticas fuertemente proteccionistas, que garantizaban a los agricultores europeos un nivel de ingresos suficiente al evitar la competencia de productos de terceros países y mediante la subvención a los precios agrícolas.

El crecimiento económico en aquellos años dependía de las exportaciones entre los países que pertenecían a la Comunidad Europea (CE). Con el objetivo de financiar la agricultura, se creó, en 1962, el Fondo Europeo de Orientación y Garantía Agrícola (FEOGA). En segundo lugar, también se establecieron, la prohibición de monopolios, algunas políticas comunes en transportes, y la concesión de algunos privilegios comerciales a los territorios coloniales de los estados miembros. El 1 de julio de 1968, se suprimieron todos los aranceles internos entre los estados comunitarios. Al mismo tiempo se adoptó un Arancel Externo Común para todos los productos procedentes de terceros países (Unión Aduanera).

El 1 de diciembre de 1969 se reunieron en La Haya los mandatarios de los seis estados miembros de la Comunidad Europea. Trece años después de la firma del Tratado de Roma, la Europa unida hizo un balance, y estableció nuevas metas para lograr la unión económica y monetaria, y la ampliación de la Comunidad. El Impulso para esta importante iniciativa venía dado por los éxitos 


\section{REVISTA VIRTUAL VIA INVENIENDI ET IUDICANDI \\ "CAMINO DEL HALLAZGO Y DEL JUICIO"}

http://viei.usta.edu.co/ E-MAIL: revistainveniendi@usantotomas.edu.co

conseguidos por la integración europea a lo largo del decenio de 1960, el buen momento de la economía internacional y por los signos de debilidad que presentaba el sistema de Bretton Woods. En octubre de 1970 se presentó el Informe Werner, que había sido redactado por un equipo de trabajo presidido por el presidente y ministro de Hacienda de Luxemburgo. El Plan Werner estableció una unión en tres fases: 1) Convertibilidad irreversible de las monedas comunitarias; 2) Centralización de la política monetaria y crediticia y 3) Puesta en circulación de una moneda común.

Los problemas monetarios internacionales entre 1971 y 1973 (especialmente por el precio del petróleo), llevaron a la flotación generalizada de las principales monedas, y la crisis energética impidió que esta dinámica avanzara según el plan propuesto. Una de las causas fue precisamente la divergencia de las políticas económicas de los países miembros de la Comunidad Europea que tuvieron un claro efecto interno en relación con los procesos de la integración europea en general. En 1975, el Informe Tindemans decía que se había logrado la extensión geográfica con las tres ampliaciones pero no se había profundizado ni fortalecido el proceso de integración. Las instituciones de los años cincuenta no habían experimentado transformaciones (salvo el parlamento Europeo, aunque todavía de forma insuficiente) ni sus competencias se habían modificado, a pesar de los nuevos problemas que aquejaban a la sociedad desde los años setenta como la crisis energética, la crisis del Sistema Monetario, la innovación tecnológica e industrial, los fuertes desequilibrios regionales que provocaba el mercado común hacia el deterioro del medio ambiente y la protección de los consumidores (Mangas A., 2004). El siguiente paso fundamental en la dirección de la Unión Económica y Monetaria de Europa fue 
REVISTA VIRTUAL VIA INVENIENDI ET IUDICANDI

"CAMINO DEL HALLAZGO Y DEL JUICIO"

http://viei.usta.edu.co/ E-MAIL: revistainveniendi@usantotomas.edu.co

dado por el Consejo Europeo del 5 de diciembre de 1978 al instaurar el Sistema Monetario Europeo (SME), cuya finalidad era estabilizar los tipos de cambio, reducir la inflación y prepararse para la unificación monetaria de la zona con estabilidad monetaria en Europa ${ }^{6}$.

En 1985 se inició una etapa de reformas a los Tratados constituyentes de la Comunidad Europea a través del ACTA ÚNICA que entro en vigencia en $1986^{7}$. Los objetivos de ésta eran: a) Hacer frente a la creciente competencia internacional, a través de la realización de un mercado interior sin fronteras que eliminase los obstáculos existentes; b) Profundizar en la construcción comunitaria; y c) En la política monetaria, la realización de la Unión Económica y Monetaria.

El Acta Única Europea revisó el Tratado de Roma para reactivar la integración europea y llevar a cabo la realización del mercado interior. Modificó las normas de funcionamiento de las instituciones europeas y amplió las competencias comunitarias, en particular, en el ámbito de la investigación y el desarrollo y el medio ambiente. También por vez primera un tratado incluyó la regulación de la cooperación Europea en materia de política exterior común conforme al régimen ordinario de Derecho internacional. El Artículo 30 del Acta Única ${ }^{8}$ nos dice "Los Estados miembros coordinarán su acción en las organizaciones internacionales y con ocasión de las conferencias internacionales. 1. Los Estados miembros defenderán en esos foros las posiciones comunes. 2. En las organizaciones

\footnotetext{
${ }^{6}$ El Sistema Monetario Europeo, nació a raíz de una Resolución del Consejo Europeo de 5 de diciembre de 1978 para solucionar los problemas internos de la comunidad Europea. Empezó a funcionar el 13 de marzo de 1979 de conformidad con un acuerdo celebrado el mismo día entre los bancos centrales de los países que formaban parte de la Comunidad. Tenía 3 objetivos fundamentales: a) Estabilizar los tipos de cambio para corregir la inestabilidad existente a través del ECU (moneda de contabilidad y de otorgar préstamos). b) Reducir la inflación con el mecanismo de tipos de cambio e intervención a través del núcleo básico del Sistema Monetario Europeo y c. Preparar mediante la cooperación la unificación monetaria europea (Euro ca1, en línea, 2007). Fondo Europeo de Cooperación Monetaria (FECOM), creado en octubre de 1972.

${ }^{7}$ El mismo año de la firma del Acta (1986), ingresaron Portugal y España, quedando conformada la Comunidad Europea por 12 países dado que en 1981 ingresó Grecia.

${ }^{8}$ Tratado de la Constitución, 2004 artículo 19._1.
} 


\section{REVISTA VIRTUAL VIA INVENIENDI ET IUDICANDI}

"CAMINO DEL HALLAZGO Y DEL JUICIO"

http://viei.usta.edu.co/ E-MAIL: revistainveniendi@usantotomas.edu.co

internacionales y en las conferencias internacionales en las que no participen todos los Estados miembros, aquellos que participen defenderán las posiciones comunes. 3. Los Estados miembros representados en organizaciones internacionales o en conferencias internacionales en las que no participen todos los Estados miembros mantendrán informados a los demás sobre cualquier cuestión de interés común".

En la década de los años 80 se destacó en la Unión Europea, la Globalización y la Integración regional que son dos procesos contradictorios. Por una parte, se presenta la transnacionalización de la producción que representa la globalización y, por otra, existe el proceso de conformación de un bloque regional. Así pues, de alguna forma, la regionalización supuso establecer nuevas fronteras, tratos especiales, regulaciones económico-jurídicas y normas, cuando la globalización se favorece de todo tipo de control y de preferencias. La explicación de la simultaneidad de estos dos procesos cabe encontrarla como la respuesta al libre comercio y como respuesta a las crisis generadas por los problemas de abastecimiento con recursos naturales, desempleo estructural, crisis energética, problemas ambientales, exclusión de capas sociales enteras, violencia urbana y descontento social. La Comunidad Europea puso en marcha mecanismos de protección de mercados en sus áreas regionales -protección hacia dentrocombinados con un planteamiento de expansión hacia el exterior, con la finalidad de reestructurar la economía en el ámbito regional para poder ser más competitivos en los mercados mundiales (González Lidia, 2006).

La creación de un mercado sin fronteras y el estrechamiento de la interdependencia económica sentaron las bases para una mayor coordinación de las políticas económicas, factor fundamental para el desarrollo de una Unión 


\section{REVISTA VIRTUAL VIA INVENIENDI ET IUDICANDI}

"CAMINO DEL HALLAZGO Y DEL JUICIO"

http://viei.usta.edu.co/ E-MAIL: revistainveniendi@usantotomas.edu.co

Económica y Monetaria. En este contexto, en la cumbre de Hannover de junio de 1988, los doce países miembros del Comunidad Europea confiaron a un comité de expertos, presididos por Jacques Delors, entonces presidente de la Comisión, la tarea de estudiar y proponer las etapas para llevar a cabo la Unión Económica Monetaria.

En $1992^{9}$ con firma del TRATADO DE LA UNIÓN EUROPEA O TRATADO DE MAASTRICHT (vigencia desde 1 de noviembre de 1993), se dio una nueva dinámica para lograr la Unión Económica y Monetaria. El objetivo declarado fue convertir el Euro en una moneda única para toda la Comunidad y el Banco Central Europeo (BCE) en el órgano que la emita como máxima autoridad monetaria con el mandato explícito de controlar la inflación.

El Tratado también estableció las condiciones de estabilidad interna y de equilibrios financieros que debían cumplir los Estados miembros para formar parte del grupo de países que accederían al nacimiento del Euro en la tercera fase con los criterios de convergencia ${ }^{10}$. Con la política económica en manos del Banco Central Europeo y bajo las restricciones que supone el pacto de estabilidad la lógica neoliberal, "la política comercial común se basó en principios uniformes, particularmente por lo que se refiere a las modificaciones arancelarias, la celebración de acuerdos arancelarios y comerciales, la consecución de la uniformidad de las medidas de liberalización, la política de

\footnotetext{
9 Ejemplo de Integración regional: El Acuerdo Espacio Económico Europeo (EEE) se firma en 1992 por la Unión Europea y los Estados de la AELC - Unión Aduanera entre Liechtenstein y Suiza-. (Parlamento Europeo, 1992).

${ }^{10}$ Los criterios de convergencia (De Borja, 2000) se relacionaban con: a). Inflación: la tasa promedio de inflación inferior o igual a 1.5\% puntos sobre el promedio de los tres Estados Miembros que tenían mejor comportamiento en materia de precios (Alemania 2.2\%, Francia $1.7 \%$ y Luxemburgo 2.1\%). b).Tipos de interés: los países que accedieron al euro tenían un tipo promedio de interés nominal a largo plazo inferior o igual a 2 puntos sobre la media del tipo a largo plazo de los tres Estados Miembros de menor inflación (Alemania 7.1\%, Francia 7.8 \% y Luxemburgo 6.2\%). c).Déficit público: el déficit público no podía exceder del $3 \%$ de su Producto Interior Bruto (PIB) a precios de mercado. d). Deuda pública: los países aspirantes debieron ajustar su deuda pública para que no fuera superior al $60 \%$ de su PIB.
} 


\section{REVISTA VIRTUAL VIA INVENIENDI ET IUDICANDI}

"CAMINO DEL HALLAZGO Y DEL JUICIO"

http://viei.usta.edu.co/ E-MAIL: revistainveniendi@usantotomas.edu.co

exportación, así como las medidas de protección comercial, y, entre ellas, las que deban adoptarse en caso de dumping y subvenciones. En el caso de que deban negociarse acuerdos con uno o varios Estados $u$ organizaciones internacionales ${ }^{11}$, la Comisión presentará recomendaciones al Consejo, que la autorizará para iniciar las negociaciones necesarias. Además, la Comisión llevará a cabo dichas negociaciones consultando a un Comité especial, designado por el Consejo para asistirla en dicha tarea y en el marco de las directrices que el Consejo pueda dirigirle" (Tratado de Maastricht, título VII Política Comercial Común, artículo 113).

En el TRATADO DE AMSTERDAM, 1997, se incluyeron las reformas propuestas del Tratado de Maastricht. La reforma se estudio en la Conferencia intergubernamental que inició en Turín (Italia) en 1996, se analizó los problemas que enfrentaba la Unión Europea. Los ciudadanos tenían ambiciosos objetivos centrados en la función de la Unión Europea en la escena internacional, la mejora del funcionamiento de las instituciones y la perspectiva de la ampliación. Así, tras quince meses de trabajo, lograron un acuerdo el 17 de junio de 1997 con la firma de un nuevo Tratado, celebrado al más alto nivel, con los jefes de Estado o de Gobierno reunidos en Consejo Europeo.

EI TRATADO DE AMSTERDAM en materia de política exterior tuvo grandes avances para responder a los desafíos del futuro como la rápida evolución de la situación internacional ${ }^{12}$, la extensión del comercio internacional hizo de la política comercial común una de las políticas más importantes de la Comunidad. En paralelo, las ampliaciones sucesivas de la Comunidad y la consolidación del

\footnotetext{
11 Ejemplo la Organización Mundial del Comercio

${ }^{12}$ Nota: En la cumbre de Lisboa de marzo de 2000, los Jefes de Gobierno de la UE acordaron un nuevo objetivo estratégico para la Unión Europea: convertirla en la economía más competitiva del mundo antes de 2010.
} 


\section{REVISTA VIRTUAL VIA INVENIENDI ET IUDICANDI}

"CAMINO DEL HALLAZGO Y DEL JUICIO"

http://viei.usta.edu.co/ E-MAIL: revistainveniendi@usantotomas.edu.co

mercado común reforzaron la posición de la Comunidad como polo de atracción y de influencia sobre las negociaciones comerciales, bilaterales con Estados terceros o multilaterales en el GATT, hoy Organización Mundial del Comercio. La Unión desarrolló pues progresivamente una densa red de relaciones comerciales a escala mundial. De ahí que la Unión Europea constituya hoy el primer actor mundial de los intercambios internacionales. En el artículo 132 del Tratado de Ámsterdam, se consideró la protección a las exportaciones, cuando se dice "sin perjuicio de los compromisos contraídos por los Estados miembros en el marco de otras organizaciones internacionales, los regímenes de ayudas concedidas por los Estados miembros a las exportaciones hacia terceros países se armonizarán progresivamente, en la medida necesaria para evitar que se falsee la competencia entre las empresas de la Comunidad. La política comercial común se basará en principios uniformes, particularmente por lo que se refiere a las modificaciones arancelarias, la celebración de acuerdos arancelarios y comerciales, la consecución de la uniformidad de las medidas de liberalización, la política de exportación, así como las medidas de protección comercial, y, entre ellas, las que deban adoptarse en caso de dumping y subvenciones" También se modifico el ámbito del procedimiento tradicional de negociación comercial en los "acuerdos con uno o varios Estados u organizaciones internacionales, la Comisión presentará recomendaciones al Consejo, que la autorizará para iniciar las negociaciones necesarias. (Europa, Tratado de Ámsterdam artículo 133, 1997).

El comercio fue uno de los primeros campos en que los países de la Unión Europea, acordaron unir su soberanía, transfiriendo a la Comisión Europea la responsabilidad de ocuparse de los asuntos comerciales, incluida la negociación 


\section{REVISTA VIRTUAL VIA INVENIENDI ET IUDICANDI}

"CAMINO DEL HALLAZGO Y DEL JUICIO"

http://viei.usta.edu.co/ E-MAIL: revistainveniendi@usantotomas.edu.co

en nombre de dichos países de los acuerdos de comercio internacionales, de manera que los Estados miembros de la Unión Europea negocian como uno solo, tanto con sus socios comerciales como en la OMC, con lo que maximizan su influencia en el ámbito internacional.

En el TRATADO DE NIZA, 2001, la política comercial común permanece en forma similar a los anteriores tratados, el cambio se observa en referencia a las relaciones comerciales con terceros países al crearse un Comité especial de consulta para realizar las negociaciones. "En el caso de que deban negociarse acuerdos con uno o varios Estados $u$ organizaciones internacionales, la Comisión presentará recomendaciones al Consejo, que la autorizará para iniciar las negociaciones necesarias. Corresponderá al Consejo y a la Comisión velar por que los acuerdos negociados sean compatibles con las políticas y normas internas de la Comunidad. La Comisión lleva a cabo dichas negociaciones consultando a un Comité especial, designado por el Consejo para asistirla en dicha área y en el marco de las directrices que el Consejo pueda dirigirle. La Comisión informará periódicamente al Comité especial sobre la marcha de las negociaciones" (Europa, Tratado de Niza, artículo 133, 2001).

\section{En el TRATADO DE LA CONSTITUCIÓN EUROPEA Y LAS INSTITUCIONES,} que se firmó el 29 de octubre de 2004 en Roma. Incluye la gobernanza económica, forma de Globalización que constituye una nueva forma de gestión de la Unión Europea. Un ejemplo de esta gestión es la realizada por los Estados y las Instituciones Multilaterales al negociar acuerdos que posteriormente se transforman en administración a nivel mundial y se convierten en toma de decisiones en forma multilateral. Se internacionaliza a través del Comercio exterior y en el tratado se habla que la Unión Aduanera permitirá el "desarrollo 


\section{REVISTA VIRTUAL VIA INVENIENDI ET IUDICANDI \\ "CAMINO DEL HALLAZGO Y DEL JUICIO"}

http://viei.usta.edu.co/ E-MAIL: revistainveniendi@usantotomas.edu.co

armonioso del comercio mundial, a la supresión progresiva de las restricciones a los intercambios internacionales y a las inversiones extranjeras directas, así como a la reducción de las barreras arancelarias y de otro tipo" (Europa, Tratado de la Constitución, 2004, artículo III-314).

La política comercial de la Unión Europea hacia terceros países se observó en sus exportaciones, por ejemplo hacia China pasan de 18.492 millones de Euros en 1998 a 81.060 millones de Euros en el 2007 con un crecimiento del 16\% en promedio en 10 años (Ver anexo No 1). Igual situación se presenta con la India, Singapur y Brasil, crecen al duplicarse, al triplicarse y 50\% respectivamente en los mismos años.

\section{Tabla No. 1}

\begin{tabular}{|c|c|c|c|c|c|c|c|c|}
\hline AÑOS & MUNDO & $\begin{array}{l}\text { ESTADOS } \\
\text { UNIDOS }\end{array}$ & CHINA & JAPON & CANADA & SINGAPUR & INDIA & BRASIL \\
\hline 1998 & 702.097 & 162.432 & 18.492 & 35.024 & 18.664 & 12.575 & 9.556 & 16.509 \\
\hline 1999 & 747.029 & 187.264 & 23.894 & 40.177 & 22.215 & 13.260 & 10.235 & 15.905 \\
\hline 2000 & 917.944 & 242.202 & 32.920 & 50.776 & 29.603 & 16.539 & 11.525 & 16.826 \\
\hline 2001 & 970.454 & 252.489 & 39.945 & 49.770 & 30.417 & 15.281 & 13.401 & 18.462 \\
\hline 2002 & 962.180 & 245.496 & 40.810 & 46.340 & 28.739 & 14.581 & 12.705 & 15.201 \\
\hline 2003 & 939.822 & 222.417 & 46.911 & 43.333 & 26.891 & 14.109 & 12.530 & 12.338 \\
\hline 2004 & 931.113 & 233.889 & 56.380 & 46.544 & 28.460 & 17.710 & 13.776 & 14.082 \\
\hline 2005 & 1.032 .467 & 255.519 & 59.127 & 47.225 & 33.309 & 18.583 & 17.614 & 16.044 \\
\hline 2006 & 1.150 .898 & 269.686 & 71.716 & 47.238 & 37.461 & 21.441 & 26.563 & 17.582 \\
\hline 2007 & 1.259 .589 & 265.758 & 81.060 & 47.496 & 36.556 & 23.792 & 32.562 & 23.495 \\
\hline
\end{tabular}

Fuente: European Commission, (2009) euro

statistical books external and intra-European trade statistical yearbook data 1958- 2007, Libro ISBN 978-92-79-11096-2. 
REVISTA VIRTUAL VIA INVENIENDI ET IUDICANDI

"CAMINO DEL HALLAZGO Y DEL JUICIO"

http://viei.usta.edu.co/ E-MAIL: revistainveniendi@usantotomas.edu.co

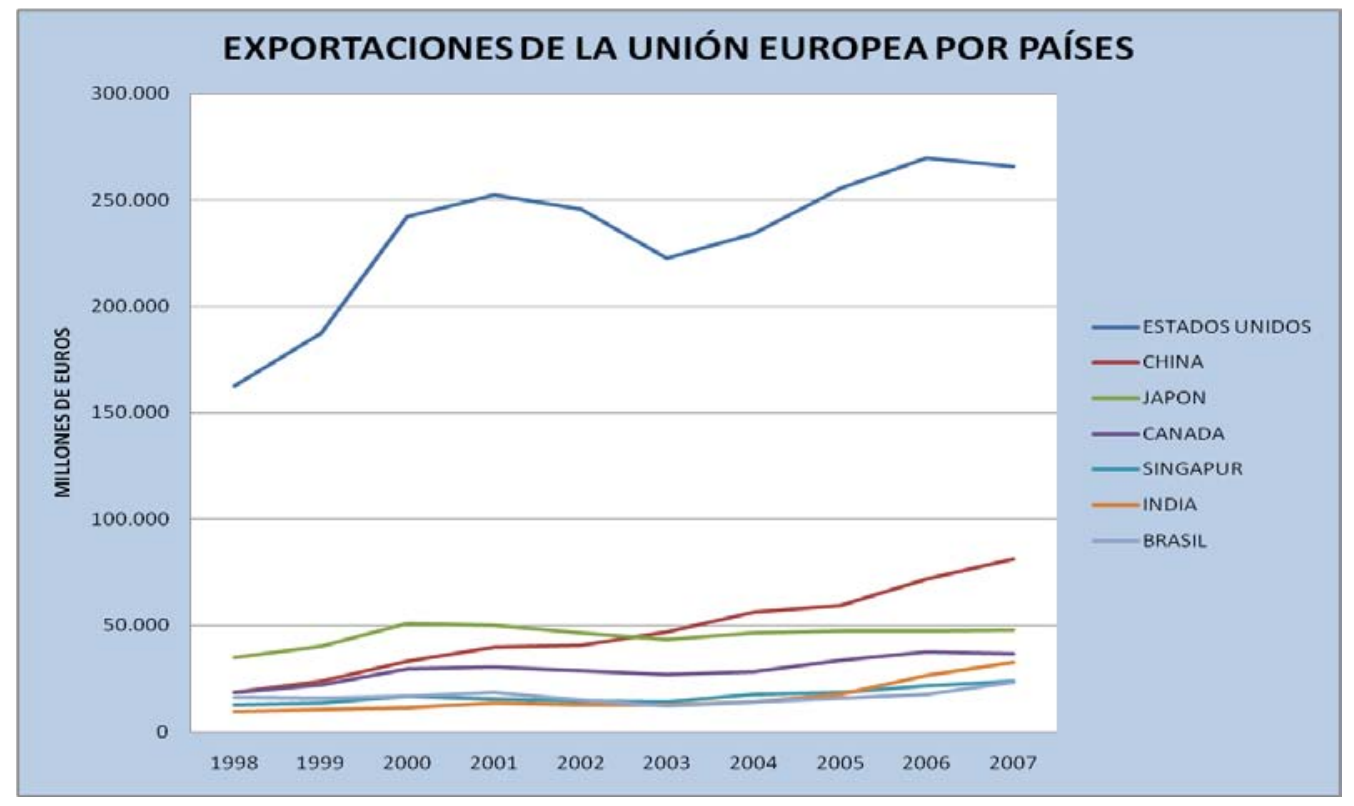




\section{REVISTA VIRTUAL VIA INVENIENDI ET IUDICANDI \\ "CAMINO DEL HALLAZGO Y DEL JUICIO"}

http://viei.usta.edu.co/ E-MAIL: revistainveniendi@usantotomas.edu.co

Fuente: European Commission, (2009) euro statistical books external and intraEuropean trade statistical yearbook data 1958- 2007, Libro ISBN 978-92-7911096-2.

Nota: Cálculos de Elisa Urbina

\section{Tabla No. 2}

\begin{tabular}{|c|c|c|c|c|c|c|c|c|}
\hline \multicolumn{9}{|c|}{$\begin{array}{l}\text { EXPORTACIONES } \\
\text { DE LA UNIÓN } \\
\text { EUROPEA } \\
\text { (Participaciones \%) }\end{array}$} \\
\hline AÑOS & $\begin{array}{l}\text { RESTO DE } \\
\text { PAIISES }\end{array}$ & $\begin{array}{l}\text { ESTADOS } \\
\text { UNIDOS }\end{array}$ & CHINA & JAPON & CANADA & SINGAPUR & INDIA & BRASIL \\
\hline 1998 & 61,08 & 23,14 & 2,63 & 4,99 & 2,66 & 1,79 & 1,36 & 2,35 \\
\hline 1999 & 58,11 & 25,07 & 3,20 & 5,38 & 2,97 & 1,78 & 1,37 & 2,13 \\
\hline 2000 & 56,38 & 26,39 & 3,59 & 5,53 & 3,22 & 1,80 & 1,26 & 1,83 \\
\hline 2001 & 56,75 & 26,02 & 4,12 & 5,13 & 3,13 & 1,57 & 1,38 & 1,90 \\
\hline 2002 & 58,03 & 25,51 & 4,24 & 4,82 & 2,99 & 1,52 & 1,32 & 1,58 \\
\hline 2003 & 59,72 & 23,67 & 4,99 & 4,61 & 2,86 & 1,50 & 1,33 & 1,31 \\
\hline 2004 & 55,88 & 25,12 & 6,06 & 5,00 & 3,06 & 1,90 & 1,48 & 1,51 \\
\hline 2005 & 56,66 & 24,75 & 5,73 & 4,57 & 3,23 & 1,80 & 1,71 & 1,55 \\
\hline 2006 & 57,28 & 23,43 & 6,23 & 4,10 & 3,25 & 1,86 & 2,31 & 1,53 \\
\hline 2007 & 59,45 & 21,10 & 6,44 & 3,77 & 2,90 & 1,89 & 2,59 & 1,87 \\
\hline
\end{tabular}




\section{REVISTA VIRTUAL VIA INVENIENDI ET IUDICANDI \\ "CAMINO DEL HALLAZGO Y DEL JUICIO"}

http://viei.usta.edu.co/ E-MAIL: revistainveniendi@usantotomas.edu.co

Las exportaciones hacia Estados Unidos se incrementan y representan entre el $21 \%$ y el $26 \%$ del total, convirtiéndose en el principal socio comercial. La diversificación de destinos también se observa en el caso de China cuando la participación asciende de 2,63\% en 1998 a 6,44\% en el 2007. Las ventas hacia la India, también crecen al pasar su participación de 1,36\% a 2,59\% en el mismo período. Situación contraria para el caso de Japón que se reduce de 4,99 \% a 3,77\% en los diez años de análisis como observamos a continuación:

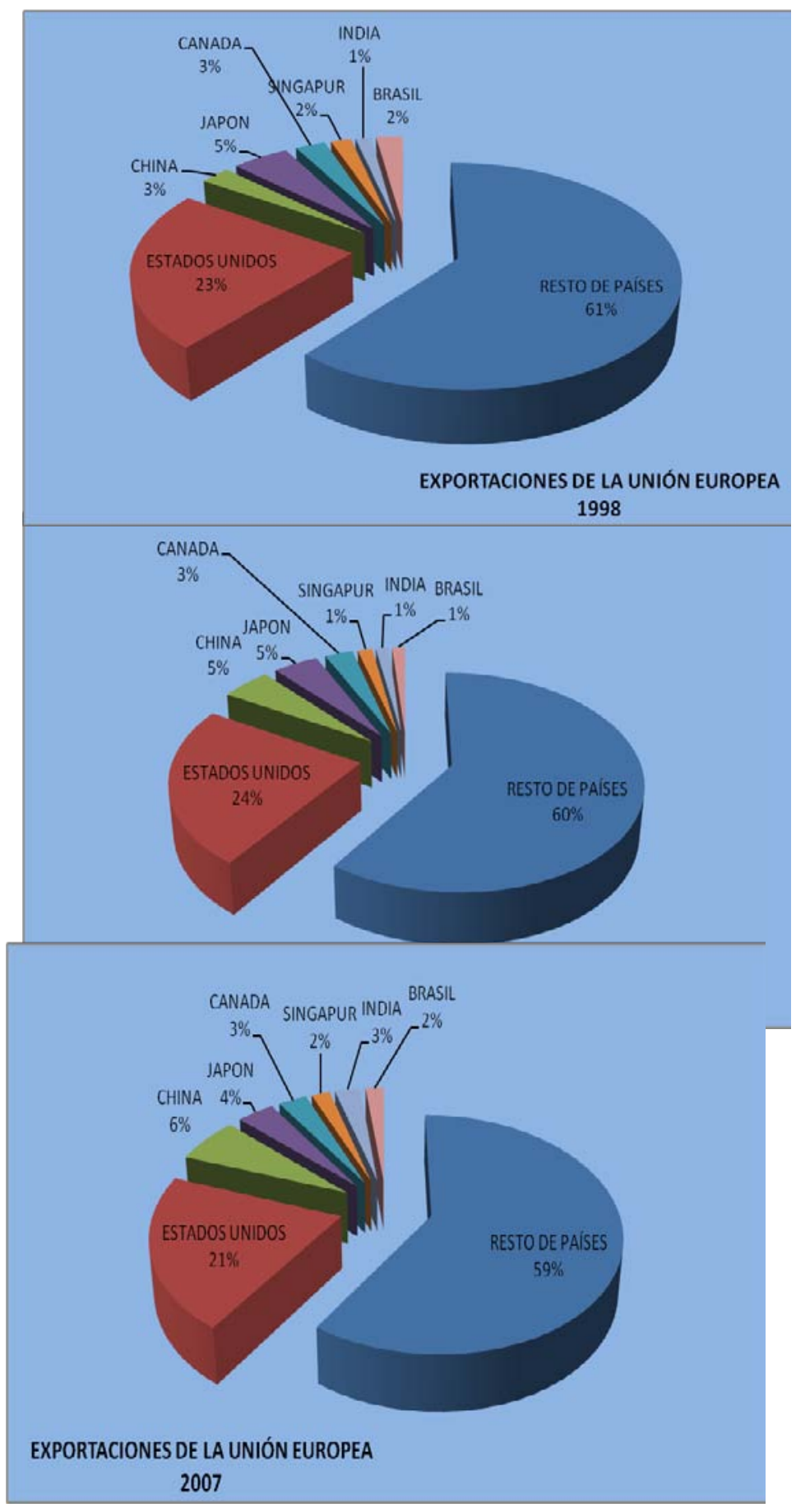


REVISTA VIRTUAL VIA INVENIENDI ET IUDICANDI

"CAMINO DEL HALLAZGO Y DEL JUICIO"

http://viei.usta.edu.co/ E-MAIL: revistainveniendi@usantotomas.edu.co

La multilateralización de las relaciones comerciales impulsada por la Organización Mundial del Comercio ${ }^{13}$ muestran la realidad económica en que prima el crecimiento hacia afuera y en el caso de la Unión Europea, combina dos fenómenos simultáneos la transnacionalización de la producción con el fortalecimiento de la integración regional. Situación que se ve en el Consejo Europeo de junio de 2005 , tras las dificultades de ratificación ${ }^{14}$ de la Constitución europea, los jefes de Estado o de Gobierno decidieron iniciar un período de reflexión sobre el futuro de Europa.

En el Consejo de los días 21 y 22 de junio de 2007 en Bruselas, se logró un acuerdo con el TRATADO DE LISBOA. Éste busca mantener elementos de la Constitución, como la creación de una presidencia de largo plazo para la Unión, un jefe de política exterior con mayores poderes para representar al bloque en el escenario mundial $y$ un mayor peso para el Parlamento Europeo y los nacionales (Insa, 2007).

El siguiente Consejo Europeo, logró el acuerdo sobre el texto del nuevo Tratado de Reforma, conocido como TRATADO DE LISBOA, ya que fue firmado el 13 de diciembre de 2007 en esa ciudad. El acuerdo intergubernamental llevó a cabo el rescate sustancial de la Constitución Europea, poniendo fin a dos años de crisis política (Aldecoa Luzarraga Y Guinea Llorente, 2008).

\footnotetext{
13 Organismo multilateral que acuden los gobiernos Miembros para tratar de arreglar los problemas comerciales que tienen entre sí. La mayor parte de la labor actual de la OMC proviene de las negociaciones celebradas en el período 1986-1994, la llamada Ronda Uruguay. Antes GATT (Acuerdo General sobre aranceles y Comercio).

${ }^{14}$ Hoy solo 13 países han ratificado el Tratado de la Unión Europea. El Consejo Europeo, formado por los mandatarios de los Estados miembros, definirá las orientaciones generales de la Unión aunque se convierte en un órgano soberano en cuanto a la definición de la política exterior.
} 


\section{REVISTA VIRTUAL VIA INVENIENDI ET IUDICANDI}

"CAMINO DEL HALLAZGO Y DEL JUICIO"

http://viei.usta.edu.co/ E-MAIL: revistainveniendi@usantotomas.edu.co

El éxito de las negociaciones se debió al trabajo desarrollado por la presidencia alemana, Ángela Merkel, que supo encontrar la ruta para salir del laberinto constitucional en que se encontraba la Unión Europea. Empezó con el envío en abril de 2007 de un cuestionario a los Veintisiete para que cada Estado plasmase sus exigencias o aspiraciones y concluyó dos meses después en una reunión del Consejo. De esta manera, la canciller alemán logro el acuerdo para que se firmara el Tratado de Lisboa (Martín y Pérez de Nanclares, 2008).

Las innovaciones fundamentales del Tratado de Lisboa para lograr una mayor coherencia de la política exterior son la personería jurídica para la Unión, el fin de los pilares, la formulación de un marco político para la acción exterior siguiendo una política de responsabilidad, la flexibilización de la toma de decisiones y la creación de dos instituciones fundamentales, el nuevo alto representante y el Servicio Europeo de Acción Exterior (Aldecoa Luzarraga y Guinea Llorente, 2008).

El desarrollo armonioso del comercio mundial, la supresión progresiva de las restricciones a los intercambios internacionales y a las inversiones extranjeras directas, así como a la reducción de las barreras arancelarias y de otro tipo, se consideran en el Tratado de Lisboa. En la "política Comercial común se hace referencia como en los anteriores Tratados, a los acuerdos arancelarios y comerciales relativos a los intercambios de mercancías y servicios, y los aspectos comerciales de la propiedad intelectual e industrial, las inversiones extranjeras directas, la uniformización de las medidas de liberación, la política de exportación, así como las medidas de protección comercial entre ellas las que deban adoptarse en el caso de dumping y subvenciones. La política comercial común se llevará a cabo en un marco de principios y objetivos de la acción 


\section{REVISTA VIRTUAL VIA INVENIENDI ET IUDICANDI}

"CAMINO DEL HALLAZGO Y DEL JUICIO"

http://viei.usta.edu.co/ E-MAIL: revistainveniendi@usantotomas.edu.co

exterior de la Unión“(Tratado de Lisboa de 2007, artículo 207). Situación que se puede mostrar con las exportaciones e importaciones hechas por la Unión Europea en los últimos diez años al integrarse al mercado mundial como se puede ver con la diversificación de las exportaciones y Balanza Comercial. La participación de Estados Unidos y Japón se reduce mientras crece la participación de las exportaciones destinadas a China y Brasil.

La Balanza comercial es deficitaria en los años 2005, 2006 y 2007 para la Unión Europea. El comercio con Estados Unidos y Canadá presenta superávit en los 10 años de análisis. Las importaciones provenientes de China, Japón y Singapur siempre superan las exportaciones realizadas. (Ver anexo 1 y 2, Crecimiento de las importaciones y las exportaciones de la Unión Europea). La acción exterior, queda clara en el Tratado de Lisboa y la política comercial va a tener mayor visibilidad en el comercio global, especialmente con las negociaciones multilaterales como en la Organización Mundial del Comercio. A continuación vemos gráficamente la Balanza comercial:

Tabla No. 3

BALANZA COMERCIAL DE LA UNIÓN EUROPEA POR PAÍSES
$\begin{gathered}\text { (Millones de } \\
\text { EUROS) }\end{gathered}$
\begin{tabular}{|c|c|c|c|c|c|c|c|c|}
\hline AÑOS & MUNDO & $\begin{array}{c}\text { ESTADOS } \\
\text { UNIDOS }\end{array}$ & CHINA & JAPON & CANADA & SINGAPUR & INDIA & BRASIL \\
\hline 1998 & 72.388 & 28.800 & -6.628 & -28.949 & 9.475 & -2.949 & 1.511 & 3.335 \\
\hline 1999 & 54.983 & 44.775 & -4.484 & -29.314 & 12.432 & -3.082 & 1.516 & 2.905 \\
\hline 2000 & 10.653 & 63.672 & -8.547 & 34.324 & 16.290 & -3.249 & 496 & 518 \\
\hline 2001 & 70.974 & 74.502 & -5.852 & 22.258 & 17.646 & -2.893 & 1.456 & 1.150 \\
\hline 2002 & 89.479 & 93.150 & 10.190 & 18.453 & 17.595 & -1.993 & 951 & -783 \\
\hline 2003 & 73.406 & 89.033 & - & - & 15.595 & -2.989 & 761 & -3.697 \\
\hline
\end{tabular}


REVISTA VIRTUAL VIA INVENIENDI ET IUDICANDI

"CAMINO DEL HALLAZGO Y DEL JUICIO"

http://viei.usta.edu.co/ E-MAIL: revistainveniendi@usantotomas.edu.co

\begin{tabular}{|l|l|l|l|l|l|l|l|l|}
\hline & & & 16.944 & 20.575 & & & & \\
\hline 2004 & 30.543 & 94.907 & -29.853 & -25.243 & 15.440 & -3.179 & 533 & -5.377 \\
\hline 2005 & -32.468 & 105.605 & 56.500 & -22.565 & 16.452 & -3.639 & 102 & -5.298 \\
\hline 2006 & -82.599 & 99.728 & -72.775 & 27.217 & 17.210 & -2.837 & 6.160 & -6.599 \\
\hline 2007 & -44.795 & 84.891 & 98.086 & 23.669 & 13.729 & 297 & 8.704 & -6.275 \\
\hline
\end{tabular}

Nota: Cálculos de Elisa Urbina

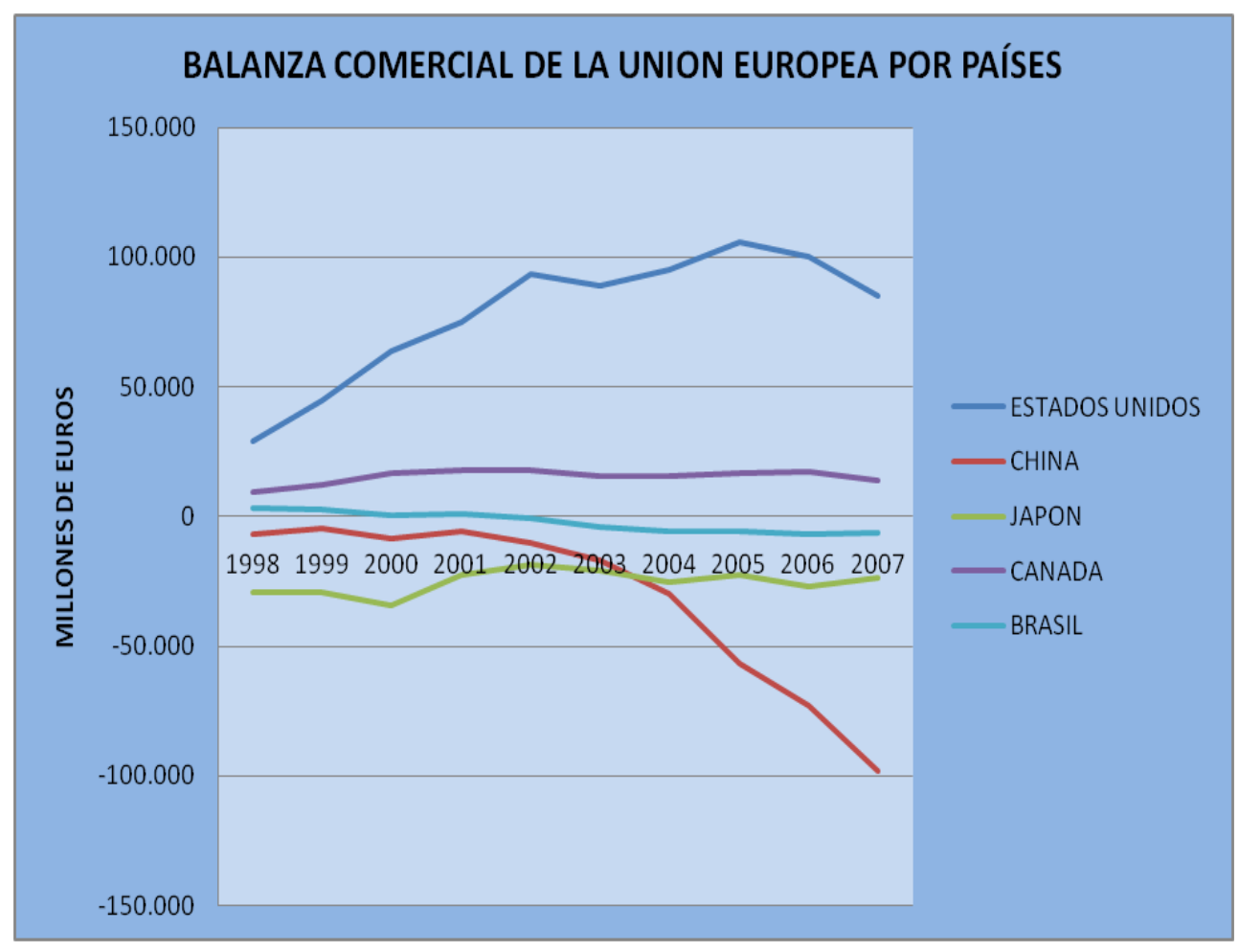




\section{REVISTA VIRTUAL VIA INVENIENDI ET IUDICANDI \\ "CAMINO DEL HALLAZGO Y DEL JUICIO"}

http://viei.usta.edu.co/ E-MAIL: revistainveniendi@usantotomas.edu.co

Fuente: European Commission, (2009) euro statistical books external and intraEuropean trade statistical yearbook data 1958-2007, Libro ISBN 978-92-7911096-2.

Nota: Cálculo de la Balanza Comercial por Elisa Urbina

En los tratados económicos, los acuerdos no son negociados por los países si no por las instituciones de la Unión Europea de acuerdo a la transferencia de soberanía que dada cada país miembro al grupo de integración. En este caso, la Gobernanza es múltiple, primero el Gobierno transfiere algunas de sus atribuciones a los organismos del grupo de integración regional y éste a su vez, las delega a un organismo internacional como el caso de la Organización Mundial del Comercio o en las negociaciones bilaterales con Estados Unidos. Las decisiones de ésta última significan el primer nivel de Gobernanza sobre las instituciones de la Unión Europea y el segundo nivel, está sobre los 27 países que integran el acuerdo de Integración y que deben ejecutar las decisiones tomadas por el organismo multilateral.

\section{III - LAS RELACIONES TRANSATLÁNTICAS}

Las relaciones económicas entre la Unión Europea y Estados Unidos son las más ligadas del mundo. Aunque este estrecho vínculo se fraguó con la Guerra Fría, la actual era de globalización que comenzó en los años ochenta ha intensificado tanto los intercambios comerciales como los flujos de capital, llegando a integrar mercados que hasta hace unas décadas permanecían cerrados al exterior.

\section{ACUERDOS CON ESTADOS UNIDOS (1990- 2008):}


REVISTA VIRTUAL VIA INVENIENDI ET IUDICANDI

"CAMINO DEL HALLAZGO Y DEL JUICIO"

http://viei.usta.edu.co/ E-MAIL: revistainveniendi@usantotomas.edu.co

Los elementos perturbadores posteriores a la Guerra Fría en las relaciones transatlánticas hacen relación al comercio internacional. Por ejemplo, en 1989 Washington gravó con impuestos una serie de productos agrícolas procedentes de la Unión Europea, después de que Bruselas prohibiera la importación de carne de vacuno tratada con hormonas.

Las diferencias entre estos países trataron de evitarse con la Declaración Transatlántica de noviembre de 1990 que por vez primera confirió carácter formal a los contactos de Estados Unidos y la Unión Europea, al convertirse en socios internacionales. Además, empiezan a tener respuesta conjunta ante un número cada vez mayor de dificultades, como la amenaza de la proliferación de armas de destrucción masiva y el terrorismo internacional, el frágil proceso de paz en Oriente Medio y la necesidad de proteger el crecimiento económico y el empleo (Comisión Europea, 2006).

En torno a la política comercial agrícola retrasaron varios años la conclusión de la Ronda de Uruguay del GATT $^{15}$ sobre Negociaciones Comerciales Multilaterales, hasta que finalmente llegaron a un acuerdo en diciembre de 1993. Más aún, la relación transatlántica se vio gravemente afectada con la proliferación de sanciones económicas unilaterales, por ejemplo en un período de tan solo cuatro años (1993-1996), se aprobaron más de 60 leyes o acciones ejecutivas que autorizaban sanciones económicas unilaterales con objetivos de

\footnotetext{
15 En 1995, la Organización Mundial del Comercio (OMC) sustituyo el GATT, Acuerdo General sobre Aranceles y Comercio, creado en 1948 como un tratado multilateral que fijaba las reglas del intercambio comercial entre los estados signatarios, en aquel momento representantes del $80 \%$ del comercio mundial. El GATT se organizó a través de las rondas de negociaciones, que podían durar varios años. En 1986, con el inicio de la Ronda Uruguay, entraron bajo la cobertura del GATT todos los aspectos de la agricultura y algunos servicios. Tanto Estados Unidos como las grandes empresas transnacionales impulsaron el nacimiento de un nuevo organismo internacional con mayor poder que el GATT y con escaso control democrático. En 1994, dentro de las negociaciones de la Ronda Uruguay, por el protocolo de Marrakech, se transforma el Tratado. Esta organización, que no pertenece al sistema de las Naciones Unidas, es el único ente de regulación internacional con un sistema jurídico propio.
} 


\section{REVISTA VIRTUAL VIA INVENIENDI ET IUDICANDI}

"CAMINO DEL HALLAZGO Y DEL JUICIO"

http://viei.usta.edu.co/ E-MAIL: revistainveniendi@usantotomas.edu.co

política exterior. Estas sanciones, dirigidas a 35 países que suponían cerca de una quinta parte de los mercados de exportación del mundo, dañaron seriamente la credibilidad de Estados Unidos y minaron su liderazgo en la liberalización del comercio multilateral, destinado principalmente a conservar abierta la fortaleza de Europa (Soeren Kern,2005).

En la Cumbre de 1995, se firmo la Nueva Agenda Transatlántica (NTA) que busco mejorar las relaciones comerciales. Esta fue concebida para crear una relación de consulta que abarcó la economía, el comercio y la seguridad, proponía acciones conjuntas en cuatro dimensiones principales: 1. promover la paz y la estabilidad, la democracia y el desarrollo en todo el mundo; 2. responder a los desafíos globales; 3 . contribuir a la expansión del comercio mundial y a unas relaciones económicas más cercanas; y 4. tender puentes a ambos lados del Atlántico (Kern, 2005).

Una de las principales características de la Nueva Agenda Transatlántica fue la amplitud de sus mecanismos. En primer lugar, las cumbres semestrales UEEE.UU. a nivel presidencial de ambos lados del Atlántico proporcionan el impulso necesario para que continuaran avanzando las relaciones. Las cumbres son preparadas por grupos de alto nivel y reúnen a los altos funcionarios responsables del comercio y de los asuntos económicos de ambas partes. Uno de los principales elementos de la formación en materia de barreras comerciales $^{16}$ en el mercado transatlántico es el Diálogo Comercial

\footnotetext{
16 Nota: Las principales barreras al comercio transatlántico no son los aranceles, sino las normas diferentes, los requisitos de pruebas y certificaciones y las diferencias en materia de regulación. Uno de los logros más importantes del dialogo es el Acuerdo de reconocimiento y certificación mutuo. Este tipo de acuerdo hace posible que los productos sean evaluados en materia de conformidad (pruebas, inspección y certificación) en la UE de acuerdo con las normas en vigor en los EE.UU. y viceversa. Cubre ámbitos tales como equipos de telecomunicaciones, ordenadores, equipos de terminal de satélite, compatibilidad electromagnética y productos sanitarios y farmacéuticos.
} 


\section{REVISTA VIRTUAL VIA INVENIENDI ET IUDICANDI}

"CAMINO DEL HALLAZGO Y DEL JUICIO"

http://viei.usta.edu.co/ E-MAIL: revistainveniendi@usantotomas.edu.co

Transatlántico. Este ha sido de utilidad para dar forma a la agenda comercial bilateral y elaborar informes para cada cumbre y transmitir sus recomendaciones a los líderes de la cumbre. Para la buena marcha del Acuerdo de reconocimiento mutuo es fundamental que exista consenso sobre la independencia de las instituciones nacionales de prueba y certificación, transparencia y libre acceso a las instituciones, así como a la información sobre procedimientos y pruebas específicas. En este ámbito aún existen, sin embargo, asuntos importantes pendientes de resolver, tales como la legislación sobre la protección de datos y la política en materia de biotecnología y seguridad de los alimentos ${ }^{17}$.

En cada cumbre se avanza en el proceso de integración y el comercio empieza a tener menos restricciones. Las principales negociaciones las podemos resumir con los siguientes hechos económicos:

- En 1998, en la Cumbre celebrada en Birmingham se habló de la Asociación Económica Transatlántica (Transatlantic Economic Partnership). Esta Asociación busco la liberalización sustancial del comercio sobre una base multilateral, allanando el camino hacia un marcado desarrollo de las relaciones comerciales entre la UE y los EE.UU.

- En noviembre de 2001, prima el enfoque multilateral y se centran en su compromiso de la nueva ronda de negociaciones comerciales multilaterales en la reunión ministerial de comercio de la OMC celebrada en Doha, Qatar.

\footnotetext{
17 En la Cumbre de Bonn de 1999 se reconoció que era insostenible, tanto para la UE como para los EE.UU., estar en pugna por un tema como los plátanos, mientras sus fuerzas militares están arriesgando la vida juntas en la búsqueda de unos valores comunes que ambos defienden. Por consiguiente, el objetivo de los líderes es acordar nuevas formas de identificar disputas comerciales dentro del proceso de la Nueva Agenda Transatlántica y poder resolverlas antes de se conviertan en guerras comerciales.
} 


\section{REVISTA VIRTUAL VIA INVENIENDI ET IUDICANDI}

"CAMINO DEL HALLAZGO Y DEL JUICIO"

http://viei.usta.edu.co/ E-MAIL: revistainveniendi@usantotomas.edu.co

- En marzo de 2002, la UE y EEUU crearon el Diálogo sobre la Reglamentación de los Mercados Financieros (Financial Markets Regulatory Dialogue), que ofrece un foro para debatir cuestiones financieras y regulatorias bilaterales con la finalidad de promover un mercado de capitales transatlántico eficaz y transparente.

- La Cumbre de junio de 2003 celebrada en Washington culminó con la firma de la Asistencia Legal Mutua (Mutual Legal Assistance, MLA) y los Acuerdos de Extradición, y propició la apertura de negociaciones sobre un Acuerdo Aéreo Transatlántico.

- En junio de 2004 en Irlanda, la Cumbre permitió crear la Hoja de Ruta para la Cooperación y Transparencia Regulatoria entre EEUU y la UE (Roadmap for US-EU Regulatory Cooperation and Transparency) en la que se esbozaban una serie de actividades de cooperación regulatoria.

- En 2006, la energía y el comercio son los temas centrales de estudio, se busca el mejoramiento de las relaciones comerciales y la seguridad del suministro energético. Teniendo en cuenta el alto consumo de energía a nivel mundial, causado sobre todo por China e India, Estados Unidos y la Unión Europea se han propuesto elaborar una estrategia conjunta para asegurar su suministro. En ese contexto se trató el acceso al petróleo y al gas, como el desarrollo de energía alternativa y el ahorro de energía.

- El canciller alemán, Ángela Merkel, propuso en enero de 2007 que la Unión Europea intensificara sus relaciones económicas con los Estados Unidos para avanzar hacia una asociación económica trasatlántica, a partir de la realidad de que los Estados Unidos son el principal socio 


\section{REVISTA VIRTUAL VIA INVENIENDI ET IUDICANDI}

"CAMINO DEL HALLAZGO Y DEL JUICIO"

http://viei.usta.edu.co/ E-MAIL: revistainveniendi@usantotomas.edu.co

comercial de la Unión Europea y cada uno de ellos el mayor inversor en el otro. En interés de la competitividad global, tiene que seguir removiendo barreras comerciales, por ejemplo en la legislación de patentes, estándares industriales o en el acceso a los mercados de bolsa. Un mercado común trasatlántico serviría eficazmente al interés de Europa (Íñiguez, 2007).

En Washington en la cumbre del 30 de abril de 2007, se hizo un repaso de los principales asuntos de la agenda política internacional, se acordó profundizar en las relaciones económicas bilaterales, se abordó la cuestión de la energía y cambio climático y se discutió en profundidad sobre las Rondas de la Organización Mundial de Comercio (hoy llamada Doha). Se firmó el llamado "Marco Económico Transatlántico" (Framework for Advancing Transatlantic Economic Integration between the EU and the USA), acuerdo de carácter político (por tanto no jurídicamente vinculante). Su objetivo esencial es acelerar el proceso de convergencia reglamentaria para reducir las barreras no arancelarias al comercio y las inversiones. Como sectores prioritarios para la cooperación reglamentaria se establecen: cosméticos, instrumental médico, automóvil, productos químicos, equipos eléctricos y nanotecnología. Para poner el acuerdo en práctica, se creó un Consejo de Cooperación Transatlántica y se prevé la puesta en marcha de una serie de proyectos piloto ("lighthouse projects") en sectores considerados prioritarios. Mediante estos proyectos tratarán de avanzar en la armonización de regímenes legales, prácticas y estándares en las áreas de cooperación económica mencionadas (propiedad intelectual, inversiones, seguridad en el comercio, mercados financieros, innovación y tecnología). 
REVISTA VIRTUAL VIA INVENIENDI ET IUDICANDI

"CAMINO DEL HALLAZGO Y DEL JUICIO"

http://viei.usta.edu.co/ E-MAIL: revistainveniendi@usantotomas.edu.co

El 9 de noviembre de 2007 la Unión Europea y Estados Unidos asumieron importantes compromisos durante la primera reunión del Consejo Económico Transatlántico ${ }^{18}$ (cooperación) celebrada en Washington. En una declaración conjunta, ambos bloques hacían hincapié en la importancia de su compromiso común para reducir las barreras al comercio y a la inversión internacionales con objeto de aumentar el nivel de vida de nuestros ciudadanos.

\section{COMERCIO DE BIENES}

Los acuerdos como el que existe entre Unión Europea y Estados Unidos han permitido desarrollar la liberación comercial, la armonización de los regímenes legales, las prácticas y los estándares en las áreas de cooperación económica en propiedad intelectual, inversiones, seguridad en el comercio, mercados financieros, innovación y tecnología.

En el intercambio de bienes los de mayor participación son especialmente, maquinaria y equipo de transporte, productos químicos, bienes manufacturados como combustible. Por ejemplo en el año 2007:

Tabla No. 4

\section{IMPORTACIONES DE LA UNIÓN EUROPEA DE ESTADOS UNIDOS}

\begin{tabular}{|l|r|r|}
\multicolumn{2}{|c|}{2007} \\
Productos por orden de importancia & \multicolumn{1}{|c|}{$\begin{array}{r}\text { Millones } \\
\text { de Euros }\end{array}$} & \multicolumn{1}{c|}{$\%$} \\
\hline Total & 180.867 & 100,00 \\
Maquinaria y equipo de transporte & 59.492 & 32,89 \\
Químicos y productos relacionados no & 34.054 & 18,83 \\
especificados & 24.544 & 13,57 \\
Otros & 22.316 & 12,34
\end{tabular}

18 Nota: El Consejo Económico Transatlántico cuenta con el asesoramiento formal de tres organizaciones conjuntas UE/EE UU de gran prestigio: Diálogo de Empresas Transatlánticas, Diálogo de Consumidores Transatlánticos y Diálogo de Legisladores Transatlánticos. 
Bienes manufacturados

Materias primas y transacciones n.e.c.

Materiales crudos no combustibles

excepto combustibles

Alimentos y animales vivos

Combustibles, minerales, lubricantes y

madera

Bebidas y Tabacos

Aceites animales y vegetales, grasas y

ceras
12.411

9.899

6,86

5,47

8.418

4,65

4.309

2,38

4.130

2,28

1.133

0,63

161 0,09

\section{Tabla No. 5}

\section{EXPORTACIONES DE LA UNIÓN EUROPEA A ESTADOS UNIDOS}

2007

\begin{tabular}{|c|c|c|}
\hline Productos por orden de importancia & $\begin{array}{c}\text { Millones } \\
\text { de } \\
\text { Euros }\end{array}$ & $\%$ \\
\hline Total & 265.758 & 100,00 \\
\hline Maquinaria y equipo de transporte & 91.333 & 34,37 \\
\hline $\begin{array}{l}\text { Químicos y productos relacionados no } \\
\text { especificados }\end{array}$ & 54.424 & 20,48 \\
\hline Otros & 28.862 & 10,86 \\
\hline Artículos misceláneos manufacturados & 27.992 & 10,53 \\
\hline Bienes manufacturados & 26.882 & 10,12 \\
\hline $\begin{array}{l}\text { Combustibles, minerales, lubricantes y } \\
\text { madera }\end{array}$ & 18.307 & 6,89 \\
\hline Bebidas y Tabacos & 7.024 & 2,64 \\
\hline Alimentos y animales vivos & 4.050 & 1,52 \\
\hline Materias primas y transacciones n.e.c. & 3.989 & 1,50 \\
\hline $\begin{array}{l}\text { Materiales crudos no combustibles excepto } \\
\text { combustibles }\end{array}$ & 2.273 & 0,86 \\
\hline Aceites animales y vegetales, grasas y ceras & 622 & 0,23 \\
\hline
\end{tabular}




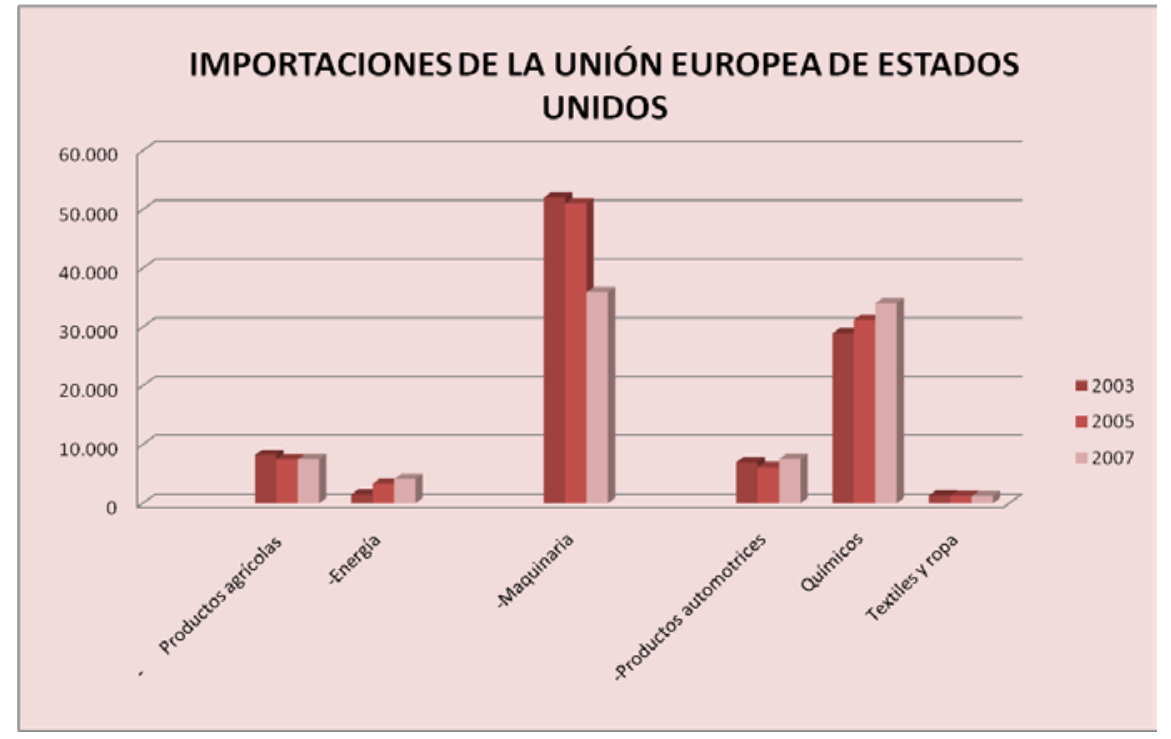

Fuente: DG TRADE statistics, (2008), Unión Europea comercio bilateral con Estados Unidos

Nota : Gráficos elaborados por Elisa Urbina 


\section{REVISTA VIRTUAL VIA INVENIENDI ET IUDICANDI \\ "CAMINO DEL HALLAZGO Y DEL JUICIO"}

http://viei.usta.edu.co/ E-MAIL: revistainveniendi@usantotomas.edu.co

Como corresponde a países con un nivel de desarrollo económico y social muy similar, el comercio de bienes entre los Estados Unidos y la Unión Europea tiene un marcado carácter intraindustrial. Dado que en términos generales la dotación relativa de factores es similar en ambas áreas geográficas, el comercio está basado en la preferencia del consumidor que existe en ambos mercados. Como se observa en el anexo 3 las Exportaciones e Importaciones por sectores económicos en los años 2003, 2005 y 2007 nos muestra similitud en relación con el comercio mundial y el que realiza con Estados Unidos, especialmente de maquinaria y equipo de transporte, productos químicos y combustibles.

\section{OBSTACULOS AL COMERCIO}

En la cumbre de junio de 2008, Estados Unidos y la Unión Europea (UE) acordaron ampliar sus lazos económicos mediante el recorte de barreras al comercio y la inversión, y también liberalizando las restricciones al comercio. Estos países hablan de la Globalización guiada por los organismos internacionales como la Organización mundial del Comercio. La próxima fase de la globalización estará dominada por las cuestiones de recursos mundiales como el agua, la energía y los alimentos. El mundo atlántico ya no es el centro del universo económico, pues éste ya no tiene centro. Las relaciones comerciales entre estos países representan el mayor flujo de intercambios de productos y bienes en todo el mundo.

El sistema multilateral de comercio ha contribuido de manera significativa al crecimiento económico, el desarrollo y el empleo a lo largo de los últimos 50 años. El sistema se creó mediante una serie de negociaciones comerciales, o 
REVISTA VIRTUAL VIA INVENIENDI ET IUDICANDI

"CAMINO DEL HALLAZGO Y DEL JUICIO"

http://viei.usta.edu.co/ E-MAIL: revistainveniendi@usantotomas.edu.co

rondas, celebradas en el marco del GATT. Las primeras rondas se centraron principalmente en las reducciones arancelarias, si bien posteriormente las negociaciones pasaron a incluir otras cuestiones como las medidas antidumping y no arancelarias. En la Ronda Uruguay, que se desarrolló entre 1986 y 1994 dio lugar a la creación de la Organización Mundial del Comercio.

La política comercial común es uno de los pilares de las relaciones exteriores de la Unión Europea. Se basa en un conjunto de normas uniformes en virtud de la unión aduanera y del arancel aduanero común y regula las relaciones comerciales de los Estados miembros con terceros países. Los instrumentos de defensa comercial y de acceso a los mercados están dirigidos, en particular, a proteger a las empresas europeas contra los obstáculos al comercio. La Unión Europea ha cambiado con la globalización; ahora su objetivo es garantizar el desarrollo armónico del comercio mundial y promover su carácter equitativo y sostenible. Asimismo, fomenta activamente la apertura de los mercados y el desarrollo de los intercambios en el marco multilateral de la Organización Mundial de Comercio (OMC).

Al mismo tiempo, apoya a los países y las regiones en desarrollo en el marco de sus relaciones bilaterales, con objeto de integrarlos en el comercio mundial a través de medidas preferenciales. En el año 2000 se iniciaron nuevas conversaciones sobre la agricultura y los servicios en una nueva Ronda "Doha" para el Desarrollo. Estas negociaciones incluye los aranceles sobre productos no agrícolas, la cuestión del comercio y el medio ambiente, normas relativas a las medidas antidumping y las subvenciones, las inversiones, la política de competencia, la facilitación del comercio, la transparencia de la contratación pública y la propiedad intelectual (OMC, 2008). 


\section{REVISTA VIRTUAL VIA INVENIENDI ET IUDICANDI}

"CAMINO DEL HALLAZGO Y DEL JUICIO"

http://viei.usta.edu.co/ E-MAIL: revistainveniendi@usantotomas.edu.co

Los Tratados de Integración son importantes para la OMC, cuando suprimen o reducen los obstáculos al comercio dentro del grupo multilateral. Reconocer los acuerdos regionales y la mayor integración económica puede beneficiar a los países. También se muestra que en determinadas circunstancias los acuerdos comerciales regionales pueden lesionar los intereses comerciales de otros países. Normalmente, el establecimiento de una unión aduanera o una zona de libre comercio violarían el principio de la OMC de igualdad de trato para todos los interlocutores comerciales, clausula de la nación más favorecida. No obstante, el artículo 24 del GATT autorizó como excepción especial el establecimiento de acuerdos comerciales regionales como el de Estados Unidos y la Unión Europea. No obstante, la interpretación de los términos de esas normas, que ha sido un elemento central de la labor del Comité de Acuerdos Comerciales Regionales, ha resultado polémica. Como consecuencia, desde 1995 el Comité trata de examinar los distintos beneficios comerciales a la luz de la OMC.

En la Declaración de Doha los países miembros convinieron en negociar una solución, prestando la debida atención a la función que esos acuerdos pueden desempeñar en el fomento del desarrollo. Las negociaciones en esta Ronda se centran especialmente en los productos agrícolas. La propuesta de Estados Unidos es un recorte de los aranceles en un 90\% y la de Europa una reducción del $60 \%$, esta oferta reduce en más de la mitad los aranceles más elevados y presiona al resto de países desarrollados a reducir sus aranceles agrícolas. El recorte aplicado al arancel medio es de $46 \%$, que pasa del $22 \%$ al $12 \%$ y supera con creces los resultados y supera los resultados obtenidos en la Ronda de Uruguay. Este recorte aumenta el acceso a los mercados de forma gradual y es 


\section{REVISTA VIRTUAL VIA INVENIENDI ET IUDICANDI \\ "CAMINO DEL HALLAZGO Y DEL JUICIO"}

http://viei.usta.edu.co/ E-MAIL: revistainveniendi@usantotomas.edu.co

menos dañino para los agricultores europeos (Unión Europea, 2005, MEMO/05/400).

La Unión Europea es abierta a la integración con Estados Unidos, situación que podemos observar a continuación con la media de las exportaciones e importaciones respecto al Producto Interno Bruto de la Unión Europea. El indicador de integración comercial de los 27 países de Europa con respecto al comercio exterior con Estados Unidos fluctúa entre 3,52\% (año 2003) y 4,57\% (año 2000). En el año 2000 las exportaciones tuvieron el mayor crecimiento $29,34 \%$ (ver anexo 1) y el PIB del mismo año aumento $7,20 \%$, las importaciones en los 10 años de análisis también presentan el mayor crecimiento ( ver anexo No2).

\section{Tabla No. 6}

INDICADOR DE INTEGRACIÓN EXTERIOR DE LA UNIÓN EUROPEA CON ESTADOS UNIDOS

(MILLONES DE EUROS)

\begin{tabular}{|c|c|c|c|c|}
\hline AÑOS & $\begin{array}{c}\text { UNION } \\
\text { EUROPEA } \\
\text {-PIB -27 } \\
\text { PAÍSES }\end{array}$ & $\begin{array}{c}\text { EXPORTACIONE } \\
\text { S A ESTADOS } \\
\text { UNIDOS }\end{array}$ & $\begin{array}{c}\text { IMPORTACIONE } \\
\text { S DE ESTADOS } \\
\text { UNIDOS }\end{array}$ & $\begin{array}{c}\text { INDICADOR } \\
* \% \\
\end{array}$ \\
\hline 1998 & 8.162 .367 & 162.432 & 133.632 & 3,63 \\
\hline 1999 & 8.583 .687 & 187.264 & 142.489 & 3,84 \\
\hline 2000 & 9.201 .966 & 242.202 & 178.530 & 4,57 \\
\hline 2001 & 9.579 .757 & 252.489 & 177.987 & 4,49 \\
\hline 2002 & $\begin{array}{l}9.941 .652 \\
10.108 .23\end{array}$ & 245.496 & 152.346 & 4,00 \\
\hline 2003 & $\begin{array}{r}2 \\
10.602 .78\end{array}$ & 222.417 & 133.384 & 3,52 \\
\hline 2004 & $\begin{array}{r}3 \\
11.063 .08\end{array}$ & 233.889 & 138.982 & 3,52 \\
\hline $\begin{array}{l}2005 \\
2006\end{array}$ & $\begin{array}{r}5 \\
11.676 .75\end{array}$ & $\begin{array}{l}255.519 \\
269.686\end{array}$ & $\begin{array}{l}149.914 \\
169.958\end{array}$ & $\begin{array}{l}3,66 \\
3,77\end{array}$ \\
\hline
\end{tabular}


REVISTA VIRTUAL VIA INVENIENDI ET IUDICANDI

"CAMINO DEL HALLAZGO Y DEL JUICIO"

http://viei.usta.edu.co/ E-MAIL: revistainveniendi@usantotomas.edu.co

\begin{tabular}{|r|r|r|r|r|} 
& 6 & & \\
2007 & 12.352 .99 & & & \\
3 & 265.758 & 180.867 & 3,62 \\
\hline
\end{tabular}

Fuente: Eurostat - Data Explorer

Nota: Indicador $=($ exportaciones + importaciones $) / P I B * 100$

Cálculos de Elisa Urbina

El elevado volumen de transacciones comerciales entre el viejo y nuevo continente ilustra el alto grado de interdependencia entre ambas economías. Las negociaciones semestrales muestran un compromiso que acercan a Estados Unidos y la Unión Europea a expandir sus lazos económicos reduciendo las cargas regulatorias y llevan a la integración económica y a eliminar las diferencias regulatorias innecesarias en unas cuarenta áreas, que incluyen dispositivos y servicios médicos, equipos eléctricos, químicos y estándares automovilísticos.

\section{IV- CONCLUSIÓN}

La política comercial común es uno de los pilares de las relaciones exteriores de la Unión Europea. Se basa en un conjunto de normas uniformes en virtud, inicialmente de la unión aduanera y hoy con la Unión Económica. El arancel externo común es uno de los elementos que regula las relaciones comerciales de los Estados miembros con terceros países. Los instrumentos de defensa comercial y de acceso a los mercados están dirigidos, en particular, a proteger a las empresas europeas contra los obstáculos al comercio.

El Acta Única Europea de 1986, revisó el Tratado de Roma para reactivar la integración europea y llevar a cabo la realización del mercado interior. Modificó las normas de funcionamiento de las instituciones europeas y amplió las 


\section{REVISTA VIRTUAL VIA INVENIENDI ET IUDICANDI \\ "CAMINO DEL HALLAZGO Y DEL JUICIO"}

http://viei.usta.edu.co/ E-MAIL: revistainveniendi@usantotomas.edu.co

competencias comunitarias, en particular, en el ámbito de la investigación y el desarrollo y el medio ambiente. También por vez primera un tratado incluyó la regulación de la cooperación Europea en materia de política exterior común conforme al régimen ordinario de Derecho internacional y coordinan sus acciones en las organizaciones internacionales.

La Unión Europea ha cambiado con la globalización; ahora su objetivo es ésta a través del comercio mundial. En la década de los años 80 se destacó en la Unión Europea, la Globalización y la Integración regional que son dos procesos contradictorios. Por una parte, se presenta la transnacionalización de la producción que representa la globalización y, por otra, existe el proceso de conformación de un bloque regional. Así pues, de alguna forma, la regionalización supuso establecer nuevas fronteras, tratos especiales, regulaciones económico-jurídicas y normas, cuando la globalización se favorece de todo tipo de control y de preferencias. La explicación de la simultaneidad de estos dos procesos cabe encontrarla como la respuesta al libre comercio y como respuesta a las crisis generadas por los problemas de abastecimiento con recursos naturales, desempleo estructural, crisis energética, problemas ambientales, exclusión de capas sociales enteras, violencia urbana y descontento social. La Comunidad Europea puso en marcha mecanismos de protección de mercados en sus áreas regionales -protección hacia dentrocombinados con un planteamiento de expansión hacia el exterior, con la finalidad de reestructurar la economía en el ámbito regional para poder ser más competitivos en los mercados mundiales.

En la mundialización influyen las políticas comerciales de los 27 países de la Unión Europea y Estados Unidos por su mayor participación en las 
REVISTA VIRTUAL VIA INVENIENDI ET IUDICANDI

"CAMINO DEL HALLAZGO Y DEL JUICIO"

http://viei.usta.edu.co/ E-MAIL: revistainveniendi@usantotomas.edu.co

exportaciones e importaciones de bienes y servicios. Las decisiones multilaterales están determinadas hoy por el poder económico del regionalismo determinado por algunos acuerdos transatlánticos y grupos de integración.

El desarrollo armonioso del comercio mundial, la supresión progresiva de las restricciones a los intercambios internacionales y a las inversiones extranjeras directas, así como a la reducción de las barreras arancelarias y de otro tipo, se consideran en los diferentes Tratados de la Unión Europea. El último del año 2007 , el Tratado de Lisboa, la política Comercial común hace referencia como en los anteriores Tratados, a los acuerdos arancelarios y comerciales relativos a los intercambios de mercancías y servicios, y los aspectos comerciales de la propiedad intelectual e industrial, las inversiones extranjeras directas, la uniformización de las medidas de liberación, la política de exportación, así como las medidas de protección comercial entre ellas las que deban adoptarse en el caso de dumping y subvenciones. La política comercial común se lleva a cabo en un marco de principios y objetivos de la acción exterior de la Unión. Situación que se puede mostrar con las exportaciones e importaciones hechas por la Unión Europea en los últimos diez años al integrarse al mercado mundial como se puede ver con la diversificación de las exportaciones y Balanza Comercial. La participación de Estados Unidos y Japón se reduce mientras crece la participación de las exportaciones destinadas a China y Brasil.

Las relaciones económicas entre la Unión Europea y Estados Unidos son las más ligadas del mundo. Aunque este estrecho vínculo se fraguó con la Guerra Fría, la actual era de globalización que comenzó en los años ochenta ha intensificado tanto los intercambios comerciales como los flujos de capital, 


\section{REVISTA VIRTUAL VIA INVENIENDI ET IUDICANDI}

"CAMINO DEL HALLAZGO Y DEL JUICIO"

http://viei.usta.edu.co/ E-MAIL: revistainveniendi@usantotomas.edu.co

llegando a integrar mercados que hasta hace unas décadas permanecían cerrados al exterior. Como corresponde a países con un nivel de desarrollo económico y social muy similar, el comercio de bienes entre los Estados Unidos y la Unión Europea tiene un marcado carácter intraindustrial. Dado que en términos generales el comercio está basado en la preferencia del consumidor que existe en ambos mercados. Situación que se observo en las Exportaciones e Importaciones por sectores económicos en los años 2003, 2005 y 2007. En el comercio en general con terceros países se vio que los productos más demandados son las maquinas y equipos de transporte, productos químicos y combustibles.

En la Declaración de Doha los países miembros convinieron en negociar una solución, prestando la debida atención a la función que esos acuerdos pueden desempeñar en el fomento del desarrollo de la Unión Europea. Las negociaciones en esta Ronda se centran especialmente en los productos agrícolas. La propuesta de Estados Unidos es un recorte de los aranceles en un $90 \%$ y la de Europa una reducción del $60 \%$, esta oferta reduce en más de la mitad los aranceles más elevados y presiona al resto de países desarrollados a reducir sus aranceles agrícolas. El recorte aplicado al arancel medio es de 46\%, que pasa del $22 \%$ al $12 \%$ y supera con creces los resultados y supera los resultados obtenidos en la Ronda de Uruguay. Este recorte aumenta el acceso a los mercados de forma gradual y es menos dañino para los agricultores europeos.

La Unión Europea es abierta a la integración con Estados Unidos, situación que pudimos ver con el indicador que considera la suma de las exportaciones más 
las importaciones respecto al Producto Interno Bruto de la Unión Europea. El indicador de integración comercial de los 27 países de Europa con respecto al comercio exterior con Estados Unidos durante 1998 al 2007, fluctuó entre 3,52\% (año 2003) y 4,57\% (año 2000). En el año 2000 las exportaciones tuvieron el mayor crecimiento $29,34 \%$ y el PIB del mismo año aumento $7,20 \%$, las importaciones en los 10 años de análisis también presentan el mayor crecimiento, 25,29\%.

Anexo 1

EXPORTACIONES DE LA UNIÓN EUROPEA POR PAISES

\begin{tabular}{|c|c|c|c|c|c|c|c|}
\hline & \multicolumn{2}{|c|}{ MUNDO } & \multicolumn{2}{|c|}{$\begin{array}{l}\text { ESTADOS } \\
\text { UNIDOS }\end{array}$} & \multicolumn{2}{|c|}{ CHINA } & JAPON \\
\hline AÑ & MILLO & CRECIMI & MILLO & CRECIMI & MILLO & CRECIMI & MILLO CRECIMI \\
\hline
\end{tabular}


REVISTA VIRTUAL VIA INVENIENDI ET IUDICANDI

"CAMINO DEL HALLAZGO Y DEL JUICIO"

http://viei.usta.edu.co/ E-MAIL: revistainveniendi@usantotomas.edu.co

\begin{tabular}{|c|c|c|c|c|c|c|c|c|}
\hline OS & $\begin{array}{c}\text { NES } \\
\text { DE } \\
\text { EURO } \\
\text { S }\end{array}$ & ENTO \% & $\begin{array}{c}\text { NES } \\
\text { DE } \\
\text { EURO } \\
\text { S }\end{array}$ & ENTO \% & $\begin{array}{c}\text { NES } \\
\text { DE } \\
\text { EURO } \\
\text { S }\end{array}$ & ENTO \% & $\begin{array}{c}\text { NES } \\
\text { DE } \\
\text { EURO } \\
\text { S }\end{array}$ & ENTO \% \\
\hline 199 & 702.0 & & 162.4 & & 18.49 & & 35.02 & \\
\hline 8 & 97 & & 32 & & 2 & & 4 & \\
\hline 199 & 747.0 & & 187.2 & & 23.89 & & 40.17 & \\
\hline 9 & 29 & 6,40 & 64 & 15,29 & 4 & 29,21 & 7 & 14,71 \\
\hline 200 & 917.9 & & 242.2 & & 32.92 & & 50.77 & \\
\hline 0 & 44 & 22,88 & 02 & 29,34 & 0 & 37,78 & 6 & 26,38 \\
\hline 200 & 970.4 & & 252.4 & & 39.94 & & 49.77 & \\
\hline 1 & 54 & 5,72 & 89 & 4,25 & 5 & 21,34 & 0 & $-1,98$ \\
\hline 200 & 962.1 & & 245.4 & & 40.81 & & 46.34 & \\
\hline 2 & 80 & $-0,85$ & 96 & $-2,77$ & 0 & 2,17 & 0 & $-6,89$ \\
\hline 200 & 939.8 & & 222.4 & & 46.91 & & 43.33 & \\
\hline 3 & 22 & $-2,32$ & 17 & $-9,40$ & 1 & 14,95 & 3 & $-6,49$ \\
\hline 200 & 931.1 & & 233.8 & & 56.38 & & 46.54 & \\
\hline 4 & 13 & $-0,93$ & 89 & 5,16 & 0 & 20,19 & 4 & 7,41 \\
\hline 200 & 1.032. & & 255.5 & & 59.12 & & 47.22 & \\
\hline 5 & 467 & 10,89 & 19 & 9,25 & 7 & 4,87 & 5 & 1,46 \\
\hline 200 & 1.150. & & 269.6 & & 71.71 & & 47.23 & \\
\hline 6 & 898 & 11,47 & 86 & 5,54 & 6 & 21,29 & 8 & 0,03 \\
\hline 200 & 1.259. & & 265.7 & & 81.06 & & 47.49 & \\
\hline 7 & 589 & 9,44 & 58 & $-1,46$ & 0 & 13,03 & 6 & 0,55 \\
\hline
\end{tabular}

\begin{tabular}{|c|c|c|c|c|c|c|c|c|}
\hline & CA & VADA & SINC & GAPUR & & IDIA & & RASIL \\
\hline & MILLO & & MILLO & & MILLO & & MILLO & \\
\hline & NES & & NES & & NES & & NES & \\
\hline & $\mathrm{DE}$ & & $\mathrm{DE}$ & & $\mathrm{DE}$ & & $\mathrm{DE}$ & \\
\hline AÑ & EURO & CRECIMI & EURO & CRECIMI & EURO & CRECIMI & EURO & CRECIMI \\
\hline OS & $\mathrm{S}$ & ENTO \% & S & ENTO \% & $\mathrm{S}$ & ENTO \% & S & ENTO \% \\
\hline 199 & 18.66 & & 12.57 & & & & 16.50 & \\
\hline 8 & 4 & & 5 & & 9.556 & & 9 & \\
\hline 199 & 22.21 & & 13.26 & & 10.23 & & 15.90 & \\
\hline 9 & 5 & 19,03 & 0 & 5,45 & 5 & 7,11 & 5 & $-3,66$ \\
\hline 200 & 29.60 & & 16.53 & & 11.52 & & 16.82 & \\
\hline 0 & 3 & 33,26 & 9 & 24,73 & 5 & 12,60 & 6 & 5,79 \\
\hline 200 & 30.41 & & 15.28 & & 13.40 & & 18.46 & \\
\hline $\begin{array}{c}1 \\
200\end{array}$ & $\begin{array}{c}7 \\
28.73\end{array}$ & 2,75 & $\begin{array}{c}1 \\
14.58\end{array}$ & $-7,61$ & $\begin{array}{c}1 \\
12.70\end{array}$ & 16,28 & $\begin{array}{c}2 \\
15.20\end{array}$ & 9,72 \\
\hline 2 & 9 & $-5,52$ & 1 & $-4,58$ & 5 & $-5,19$ & 1 & $-17,66$ \\
\hline 200 & 26.89 & & 14.10 & & 12.53 & & 12.33 & \\
\hline 3 & 1 & $-6,43$ & 9 & $-3,24$ & 0 & $-1,38$ & 8 & $-18,83$ \\
\hline 200 & 28.46 & & 17.71 & & 13.77 & & 14.08 & \\
\hline 4 & 0 & 5,83 & 0 & 25,52 & 6 & 9,94 & 2 & 14,14 \\
\hline 200 & 33.30 & & 18.58 & & 17.61 & & 16.04 & \\
\hline 5 & 9 & 17,04 & 3 & 4,93 & 4 & 27,86 & 4 & 13,93 \\
\hline 200 & 37.46 & & 21.44 & & 26.56 & & 17.58 & \\
\hline 6 & 1 & 12,47 & 1 & 15,38 & 3 & 50,81 & 2 & 9,59 \\
\hline 200 & 36.55 & $-2,42$ & 23.79 & 10,96 & 32.56 & 22,58 & 23.49 & 33,63 \\
\hline
\end{tabular}


REVISTA VIRTUAL VIA INVENIENDI ET IUDICANDI

"CAMINO DEL HALLAZGO Y DEL JUICIO"

http://viei.usta.edu.co/ E-MAIL: revistainveniendi@usantotomas.edu.co

\begin{tabular}{|l|l|l|l|l|l}
7 & 6 & 2 & 2 & 5 \\
\hline
\end{tabular}

Fuente: European Commission, (2009) euro statistical books external and intra-

European trade statistical yearbook data 1958-2007, Libro ISBN 978-92-7911096-2.

Nota: Cálculos de crecimiento de Elisa Urbina 
REVISTA VIRTUAL VIA INVENIENDI ET IUDICANDI

"CAMINO DEL HALLAZGO Y DEL JUICIO"

http://viei.usta.edu.co/ E-MAIL: revistainveniendi@usantotomas.edu.co

Anexo 2

IMPORTACIONES DE LA UNIÓN EUROPEA

\begin{tabular}{|c|c|c|c|c|c|c|}
\hline & \multicolumn{2}{|c|}{ MUNDO } & \multicolumn{2}{c|}{ ESTADOS UNIDOS } & \multicolumn{2}{c|}{ CHINA } \\
\hline & $\begin{array}{c}\text { MILLONES } \\
\text { DE } \\
\text { EUROS }\end{array}$ & $\begin{array}{c}\text { CRECIMIENTO } \\
\%\end{array}$ & $\begin{array}{c}\text { MILLONES } \\
\text { DE } \\
\text { EUROS }\end{array}$ & $\begin{array}{c}\text { CRECIMIENTO } \\
\%\end{array}$ & $\begin{array}{c}\text { MILLONES } \\
\text { DE } \\
\text { EUROS }\end{array}$ & $\begin{array}{c}\text { CRECIMIENTO } \\
\%\end{array}$ \\
\hline 1998 & 629.709 & & 133.632 & & 25.120 & \\
1999 & 692.046 & 9,90 & 142.489 & 6,63 & 28.378 & 12,97 \\
2000 & 907.291 & 31,10 & 178.530 & 25,29 & 41.467 & 46,12 \\
2001 & 899.480 & $-0,86$ & 177.987 & $-0,30$ & 45.797 & 10,44 \\
2002 & 872.701 & $-2,98$ & 152.346 & $-14,41$ & 51.000 & 11,36 \\
2003 & 866.416 & $-0,72$ & 133.384 & $-12,45$ & 63.855 & 25,21 \\
2004 & 900.570 & 3,94 & 138.982 & 4,20 & 86.233 & 35,05 \\
2005 & 1.064 .935 & 18,25 & 149.914 & 7,87 & 115.627 & 34,09 \\
2006 & 1.233 .497 & 15,83 & 169.958 & 13,37 & 144.491 & 24,96 \\
2007 & 1.304 .384 & 5,75 & 180.867 & 6,42 & 179.146 & 23,98 \\
\hline
\end{tabular}

\begin{tabular}{|c|c|c|c|c|c|c|}
\hline & \multicolumn{2}{|c|}{ CANADA } & \multicolumn{2}{c|}{ SINGAPUR } & \multicolumn{2}{c|}{ INDIA } \\
\hline \multirow{2}{*}{$\begin{array}{c}\text { MILLONES } \\
\text { DE } \\
\text { EUROS }\end{array}$} & $\begin{array}{c}\text { CRECIMIENTO } \\
\%\end{array}$ & $\begin{array}{c}\text { MILLONES } \\
\text { DE } \\
\text { EUROS }\end{array}$ & $\begin{array}{c}\text { CRECIMIENTO } \\
\%\end{array}$ & $\begin{array}{c}\text { MILLONES } \\
\text { DE } \\
\text { EUROS }\end{array}$ & $\begin{array}{c}\text { CRECIMIENTO } \\
\%\end{array}$ \\
\hline 1998 & 9.189 & & 15.524 & & 8.045 & \\
1999 & 9.783 & 6,46 & 16.342 & 5,27 & 8.719 & 8,38 \\
2000 & 13.313 & 36,08 & 19.788 & 21,09 & 11.029 & 26,49 \\
2001 & 12.771 & $-4,07$ & 18.174 & $-8,16$ & 11.945 & 8,31 \\
2002 & 11.144 & $-12,74$ & 16.574 & $-8,80$ & 11.754 & $-1,60$ \\
2003 & 11.296 & 1,36 & 17.098 & 3,16 & 11.769 & 0,13 \\
2004 & 13.020 & 15,26 & 20.889 & 22,17 & 13.243 & 12,52 \\
2005 & 16.857 & 29,47 & 22.222 & 6,38 & 17.512 & 32,24 \\
2006 & 20.251 & 20,13 & 24.278 & 9,25 & 20.403 & 16,51 \\
2007 & 22.827 & 12,72 & 23.495 & $-3,23$ & 23.858 & 16,93 \\
\hline
\end{tabular}




\section{REVISTA VIRTUAL VIA INVENIENDI ET IUDICANDI \\ "CAMINO DEL HALLAZGO Y DEL JUICIO"}

http://viei.usta.edu.co/ E-MAIL: revistainveniendi@usantotomas.edu.co

Fuente: European Commission, (2009) euro statistical books external and intra-

European trade statistical yearbook data 1958-2007, Libro ISBN 978-92-79$11096-2$

\section{ANEXO No 3}

IMPORTACIONES DE LA UNIÓN EUROPEA DE ESTADOS UNIDOS

\begin{tabular}{|c|c|c|}
\hline Productos por orden de importancia & $\begin{array}{l}\text { Millones } \\
\text { de } \\
\text { Euros }\end{array}$ & $\%$ \\
\hline Total & 180.867 & 100,00 \\
\hline $\begin{array}{l}\text { Maquinaria y equipo de transporte } \\
\text { Químicos y productos relacionados no } \\
\text { especificados }\end{array}$ & $\begin{array}{l}59.492 \\
34.054\end{array}$ & $\begin{array}{l}32,89 \\
18,83\end{array}$ \\
\hline Otros & 24.544 & 13,57 \\
\hline Artículos misceláneos manufacturados & 22.316 & 12,34 \\
\hline Bienes manufacturados & 12.411 & 6,86 \\
\hline $\begin{array}{l}\text { Materias primas y transacciones n.e.c. } \\
\text { Materiales crudos no combustibles } \\
\text { excepto combustibles }\end{array}$ & $\begin{array}{l}9.899 \\
8.418\end{array}$ & $\begin{array}{l}5,47 \\
4,65\end{array}$ \\
\hline $\begin{array}{l}\text { Alimentos y animales vivos } \\
\text { Combustibles, minerales, lubricantes y } \\
\text { madera }\end{array}$ & 4.309 & 2,38 \\
\hline $\begin{array}{l}\text { Bebidas y Tabacos } \\
\text { Aceites animales y vegetales, grasas y } \\
\text { ceras }\end{array}$ & 1.133 & $\begin{array}{l}0,63 \\
0,09 \\
\end{array}$ \\
\hline
\end{tabular}

EXPORTACIONES DE LA UNIÓN EUROPEA A ESTADOS UNIDOS

\begin{tabular}{|l|r|r|}
\hline \multicolumn{2}{|c|}{2007} \\
\hline Productos por orden de importancia & $\begin{array}{c}\text { Millones } \\
\text { de } \\
\text { Euros }\end{array}$ & \multicolumn{1}{c|}{$\%$} \\
\hline Total & 265.758 & 100,00 \\
Maquinaria y equipo de transporte & 91.333 & 34,37 \\
Químicos y productos relacionados no & 54.424 & 20,48 \\
especificados & 28.862 & 10,86 \\
Otros & 27.992 & 10,53
\end{tabular}




\begin{tabular}{l|r|r|} 
Bienes manufacturados & 26.882 & 10,12 \\
Combustibles, minerales, lubricantes y & 18.307 & 6,89 \\
madera & 7.024 & 2,64 \\
Bebidas y Tabacos & 4.050 & 1,52 \\
Alimentos y animales vivos & 3.989 & 1,50 \\
Materias primas y transacciones n.e.c. & & \\
Materiales crudos no combustibles & 2.273 & 0,86 \\
excepto combustibles & & \\
Aceites animales y vegetales, grasas y & 622 & 0,23 \\
ceras
\end{tabular}

Fuente: DG TRADE statistics , (2008), Unión

Europea comercio bilateral con Estados Unidos

\section{ANEXO No 3}

\section{IMPORTACIONES DE LA UNIÓN EUROPEA DEL MUNDO}

\begin{tabular}{|l|r|r|}
\hline \multicolumn{2}{|c|}{2007} \\
Productos por orden de importancia & $\begin{array}{r}\text { Millones } \\
\text { de Euros }\end{array}$ & \multicolumn{1}{c|}{$\%$} \\
\hline Total & 1.259 .589 & 100,00 \\
Combustibles, minerales, lubricantes y madera & 332.601 & 26,41 \\
Maquinaria y equipo de transporte & 269.579 & 21,40 \\
bienes manufacturados & 181.363 & 14,40 \\
Artículos misceláneos manufacturados & 175.487 & 13,93 \\
Químicos y productos relacionados no & 113.274 & 8,99 \\
especificados & 63.542 & 5,04 \\
Alimentos y animales vivos & & \\
Materiales crudos no combustibles excepto & 60.864 & 4,83 \\
combustibles & 31.480 & 2,50 \\
Materias primas y transacciones n.e.c. & 18.799 & 1,49 \\
Otros & 6.632 & 0,53 \\
Bebidas y Tabacos & 5.968 & 0,47 \\
\hline Aceites animales y vegetales, grasas y ceras & &
\end{tabular}

EXPORTACIONES DE LA UNIÓN EUROPEA AL MUNDO

2007

\begin{tabular}{|l|l|l|}
\hline Productos por orden de importancia & $\begin{array}{l}\text { Millones } \\
\text { de Euros }\end{array}$ & $\%$ \\
\hline
\end{tabular}


REVISTA VIRTUAL VIA INVENIENDI ET IUDICANDI

"CAMINO DEL HALLAZGO Y DEL JUICIO"

http://viei.usta.edu.co/ E-MAIL: revistainveniendi@usantotomas.edu.co

\begin{tabular}{|l|r|r|} 
Total & 1.304 .384 & 100,00 \\
Maquinaria y equipo de transporte & 432.279 & 33,14 \\
Otros & 208.460 & 15,98 \\
Químicos y productos relacionados no & 188.979 & 14,49 \\
especificados & 165.008 & 12,65 \\
Bienes manufacturados & 122.325 & 9,38 \\
Artículos misceláneos manufacturados & 62.499 & 4,79 \\
Combustibles, minerales, lubricantes y madera & 41.854 & 3,21 \\
Alimentos y animales vivos & 34.316 & 2,63 \\
Materias primas y transacciones n.e.c. & & \\
Materiales crudos no combustibles excepto & 26.642 & 2,04 \\
combustibles & 19.463 & 1,49 \\
Bebidas y Tabacos & 2.559 & 0,20 \\
Aceites animales y vegetales, grasas y ceras & \multicolumn{2}{|l}{$\mid$}
\end{tabular}

Fuente: DG TRADE statistics , (2008), Unión

Europea comercio bilateral con Estados Unidos

Nota: Cálculos de crecimiento por Elisa Urbina

\section{REFERENCIAS BIBLIOGRÁFICAS}

- Aldecoa Luzarraga Francisco Y Guinea Llorente Mercedes, (2008), El rescate sustancial de la Constitución Europea a través del Tratado de Lisboa: la salida del laberinto, Real Instituto Elcano Documento de Trabajo No 9/2008, recuperado julio 1 de 2008,

http://www.realinstitutoelcano.org/documentos/DT2008/DT92008 Aldecoa Guinea Tratado Lisboa.pdf

- Agroterra, (2008), La UE, inquieta por el auge del proteccionismo - El comercio, en el programa de la Cumbre UE-EE.UU, recuperado 6 de 


\section{REVISTA VIRTUAL VIA INVENIENDI ET IUDICANDI}

"CAMINO DEL HALLAZGO Y DEL JUICIO"

http://viei.usta.edu.co/ E-MAIL: revistainveniendi@usantotomas.edu.co

agosto de 2008,

http://www.agroterra.com/profesionales/articulos.asp? Idarticulo=625

- Badajoz Diputación, (2004) Unión Europea, recuperado mayo de 2007 http://www.dip-badajoz.es/, 2004.

- Batiste Harguindéguy Jean, (2007) El concepto de subsidiariedad en la política regional de la Unión Europea. Una comparación España-Francia, revista ciencias jurídicas y sociales, No 3 de abril de 2007, recuperado julio 10 de 2008, http://www.socius.es/numeros/numero 3/nvwpol.pdf

- Calvo Hornero Antonia, (2001), Organización de la Unión Europea, Segunda Edición, Centro de Estudios Ramón Areces, S.A.

- Charles W. L. Hill, (1999), Negocios Internacionales, McGraw-Hill, Tercera Edición.

- Comisión De Las Comunidades Europeas, (2001), Síntesis del Tratado de Niza, El Secretario General, Bruselas, 18 de enero de 2001, SEC (2001) 99

- Comisión Europea,( 2002), La globalización en beneficio de todos La Unión Europea y el comercio mundial, Europa en movimiento Dirección General de Prensa y Comunicación, recuperado 6 de agosto de 2007, http://ec.europa.eu/publications/booklets/move/37/es.doc

- Comisión Europea, ( 2006), La Unión Europea y los Estados Unidos Socios mundiales con responsabilidades mundiales, recuperado en 6 de agosto de 2008 http://Europa.eu.int/comm/external relations/us/intro/index.htm 


\section{REVISTA VIRTUAL VIA INVENIENDI ET IUDICANDI}

"CAMINO DEL HALLAZGO Y DEL JUICIO"

http://viei.usta.edu.co/ E-MAIL: revistainveniendi@usantotomas.edu.co

- Comisión Europea, ( 2008), Empresa e Industria, recuperado el 15 de agosto de 2008, http://ec.europa.eu/enterprise/library/ee_online/art47_es.htm

- De Borja Hidalgo Mozos Francisco, (2000), La Unión Económica y Monetaria: Una cuestión candente, Universidad de Burgos, España.

- Europa, Tratado de Niza, (en línea), disponible en http://europa.eu/scadplus/nice treaty/introduction es.htm ,

- $\quad$ EURO CAL, ( 2007 ), La Unión Monetaria Europea. Antecedentes en línea) disponible en $\quad \underline{\text { http://www.dip- }}$ badajoz.es/eurolocal/estxt/emu/antecedentes/sme.htm

- Europa, ( 2008), Tratado de Lisboa, llevar a Europa al siglo XXI , El Tratado en pocas palabras, recuperado julio 4 de 2008, http://europa.eu/lisbon treaty/glance/index es.htm

- Europa, (1992) Tratado de la Unión Europea, Diario Oficial n C 191 de 29 de julio de 1992, recuperado marzo 14 de 2009, http://eur$\underline{\text { lex.europa.eu/es/treaties/dat/11992M/htm/11992M.html\#0001000001 }}$

- Europa, ( 1997), Tratado de Ámsterdam por el que se modifican el Tratado de la Unión Europea, los Tratados Constitutivos de las Comunidades Europeas y determinados actos conexos, diario oficial $\mathrm{n}^{\circ}$ c 340 de 10 de noviembre de 1997, recuperado en marzo 14 de 2009, http://eur$\underline{\text { lex.europa.eu/es/treaties/dat/11997E/htm/11997E.htm/\#0173010078 }}$ 


\section{REVISTA VIRTUAL VIA INVENIENDI ET IUDICANDI}

"CAMINO DEL HALLAZGO Y DEL JUICIO"

http://viei.usta.edu.co/ E-MAIL: revistainveniendi@usantotomas.edu.co

- Europa , (2004), Tratado que establece la Constitución, , artículo III-314, diario oficial $n^{\circ}$ c 310 de 16 de diciembre de 2004, recuperado en marzo 14 de 209, http://eur-

lex.europa.eu/JOHtml.do?uri=OJ:C:2004:310:SOM:ES:HTML

- García Monserrat, (2007 ), La política comercial de la Unión Europea: hacia un comercio más justo para todos, OASIS No 12 , Centro de investigaciones y Proyectos Especiales, CIPE, Facultad de Finanzas, Gobierno y Relaciones Internacionales. Universidad Externado de Colombia recuperado julio 2 de 2008,

http://www.uexternado.edu.co/finanzas gob/cipe/oasis/oasis 2006 071/C ap\%204\%20Art\%203\%20(347-358).pdf

- González Lidia, ( 2006), La Constitución Europea como un proceso de Globalización, (recuperado el 5 de agosto de 2007), http://www.iij.derecho.ucr.ac.cr/archivos/documentacion/reforma\%20del\% $\underline{20 e s t a d o / 2005 /}$

- Insa Mérida Fredesvinda, (2007), La ciudadanía europea en el Tratado de Ámsterdam, Departamento de Sociología y Análisis de las Organizaciones, Universidad de Barcelona, recuperado 6 de agosto de 2007, http://www.ub.es/epp/lea/ciue.doc

- I Iñiguez Diego, ( 20007), Hacia una “Asociación Económica Transtlántica , Real Instituto Elcano, DT No 22/2007 - 30/05/2007, recuperado junio 8 de 2008, http://www.realinstitutoelcano.org/wps/portal/rielcano/contenido?WCM_G 


\section{REVISTA VIRTUAL VIA INVENIENDI ET IUDICANDI}

"CAMINO DEL HALLAZGO Y DEL JUICIO"

http://viei.usta.edu.co/ E-MAIL: revistainveniendi@usantotomas.edu.co

\section{LOBAL CONTEXT=/Elcano es/Zonas es/EEUU-}

\section{$\underline{\text { Dialogo+Trasatlantico/DT+22-2007 }}$}

- Kern Soeren, (2005), Por qué debería reformarse la Nueva Agenda Transatlántica, y por qué no se reformará (ARI), Real Instituto Elcano, ARI No 51-2005 - 4/5/2005, recuperado mayo 30 de 2008, http://www.realinstitutoelcano.org/wps/portal/rielcano/contenido?WCM G LOBAL CONTEXT=/Elcano es/Zonas es/EEUU-

Dialogo+Trasatlantico/ARI+51-2005

- Lukor, ( 2008), Noticias de Europa , recuperado septiembre 2 de 2008, http://www.lukor.com/not-mun/europa/portada/08060925.htm

- Maxé Vanesa y Miró Xavier, Opcions on line, ( marzo- abril, 2002) ¿Quién gobierna Europa? La ERT, el grupo de presión más influyente en la Unión Europea, recuperado agosto 9 de 2007, $\underline{\text { http://cric.pangea.org/cast/articulos/ert.html }}$

- Mangas Martín Araceli y Liñan nogueras diego J, Instituciones y Derecho de la Unión Europea, Tecnos, Madrid España.

- Martín y Pérez de Nanclares José, (2008), Antecedentes del Tratado de Lisboa, Real Instituto Alcano, recuperado junio 6 de 2008, http://www.realinstitutoelcano.org

- Muns Joaquín ( 2006), Del Plan Werner al euro o la historia de la larga marcha hacia la Unión Monetaria Europea, Universidad de Barcelona, $\begin{array}{lllll}\text { recuperado } & \text { agosto } & 10 & \text { de }\end{array}$ $\underline{\text { Http://www.pdf.lacaixa.comunicacions.com/ee/esp/ee09 c1 esp.pdf }}$ 
REVISTA VIRTUAL VIA INVENIENDI ET IUDICANDI

"CAMINO DEL HALLAZGO Y DEL JUICIO"

http://viei.usta.edu.co/ E-MAIL: revistainveniendi@usantotomas.edu.co

- Niza Escobar José Antonio, (2004), REVELION Las trampas de la Constitución Europea, recuperado agosto 6 de 2007, http://www.rebelion.org/noticia.php?id=7663

- OMC,(2001), CONFERENCIA MINISTERIAL Cuarto período de sesiones Doha, 9 - 14 de noviembre de 2001, recuperado agosto 6 de 2008, http://www.wto.org/spanish/thewto s/minist s/min01 s/minded s.pdf

- OMC, (2008) Informe sobre el Comercio Mundial El Comercio en un proceso de Globalización, recuperado agosto 20 de 2008, www.wto.org.

- Ocaña Juan C, (2007), El Tratado de Roma y la evolución de la C.E.E. (1957-1986), recuperado agosto 4 de 2007, http://clio.rediris.es/udidactica/traroma.htm\#Problema\%20británico

- Parlamento Europeo, (1999) Los Estados Unidos de América y el Canadá, recuperado julio 3 de 2008, http://www.europarl.europa.eu/factsheets/6 37 es.htm

- $\quad$ Secretaría delegación del Parlamento Europeo en la convención ( 2004), Resumen de la Constitución Europea, recuperado agosto 2 de 2008, http://europa.eu/institutional reform/index en.htm

- Steinberg Federico, (2008) Relaciones económicas entre la Unión Europea y Estados Unidos (ARI), Real Instituto Alcano, ARI No 16/2008, $\begin{array}{llll}\text { recuperado mayo } & 30 & \text { de }\end{array}$ http://www.realinstitutoelcano.org/wps/portal/rielcano/contenido?WCM G

LOBAL CONTEXT=/Elcano es/Zonas es/EEUU-

$\underline{\text { ialogo+Trasatlantico/ARI16-2008 }}$

- Tugores Juan, (1999), Economía internacional Globalización e Integración Regional, McGraw Hill, Cuarta edición. 
REVISTA VIRTUAL VIA INVENIENDI ET IUDICANDI

"CAMINO DEL HALLAZGO Y DEL JUICIO"

http://viei.usta.edu.co/ E-MAIL: revistainveniendi@usantotomas.edu.co

- Usinfo.state, ( 2007), EE.UU. y Unión Europea reducirán barreras comerciales, recuperado en julio 28 de 2007, $\underline{\text { http://usinfo.state.gov/xarchives/display.html?p=washfile- }}$ spanish \&y=2007\&m=may\&x=20070501113038apii0.5127832 
ÍNDICE

Página

I -INTRODUCCIÓN

4

II -POLÍTICAS COMERCIALES EN LOS TRATADOS DE

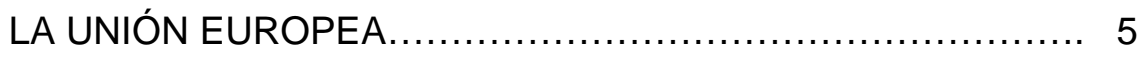

III- RELACIONES TRANSATLÁNTICAS ....................... 26

- ACUERDOS CON ESTADOS UNIDOS

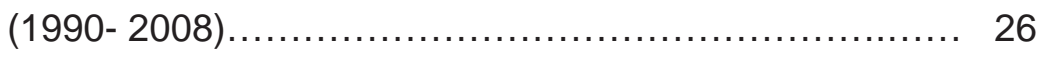

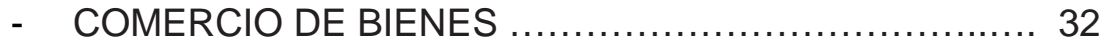

- OBStaculos Al COMERCIO EXTERIOR................ 35

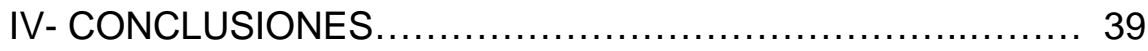


ÍNDICE DE TABLAS

Página

TABLA No. 1: EXPORTACIONES DE LA UNIÓN

EUROPEA POR PAIISES

TABLA No. 2: EXPORTACIONES DE LA

UNIÓN EUROPEA.

20

TABLA No. 3: BALANZA COMERCIAL DE LA UNIÓN

EUROPEA POR PAÍSES

24

TABLA No. 4: IMPORTACIONES DE LA UNIÓN

EUROPEA DE ESTADOS UNIDOS .33

TABLA No. 5: EXPORTACIONES DE LA UNIÓN

EUROPEA A ESTADOS UNIDOS. 33

TABLA No. 6: INDICADOR DE INTEGRACIÓN EXTERIOR

DE LA UNIÓN EUROPEA CON ESTADOS UNIDOS 39 